\title{
Redes e Capacidade de Ação na Sociedade Civil O caso de São Paulo - Brasil
}

\author{
Adrian Gurza Lavalle - FFLCH-USP e CEBRAP \\ Graziela Castello - UNICAMP e CEBRAP \\ Renata Mirandola Bichir - IUPERJ e CEM-CEBRAP ${ }^{1}$
}

\section{Resumo}

A despeito do notável sucesso político e analítico da categoria "sociedade civil" nos últimos anos, sabe-se surpreendentemente pouco acerca do modus operandi das organizações civis reais, mesmo daquelas que têm sido constantemente salientadas na literatura devido ao seu protagonismo inédito. Contra esse pano de fundo e a partir de estratégia de análise de redes aplicada aos resultados de survey realizado com 202 organizações civis na cidade de São Paulo, este artigo identifica quais os principais protagonistas do universo das organizações civis, e, sobretudo, quais as diferentes lógicas de atuação e dinâmicas internas de interação que os caracterizam. No universo de todos os atores colhidos na amostra encontrou-se, como seria de se esperar pela literatura, que as ONGs compõem o elenco dos atores com maior capacidade de atuação na rede; entretanto, pouca ou nenhuma atenção tem sido prestada às articuladoras, reveladas pela pesquisa como uma inovação recente na criação de atores coletivos -inovação notavelmente bem sucedida. Ademais, os movimentos sociais emergiram na pesquisa como os atores mais centrais da rede, a despeito da sua suposta perda de protagonismo, diagnosticada e tida como certa na literatura a partir dos anos 1990. Os três tipos de entidades cumulam diferentes vantagens estruturais no universo das organizações civis, mas são centrais por motivos diferentes; eles desempenham papeis diferentes e são desigualmente importantes em relação aos os outros tipos de organizações civis periféricas ou de centralidade intermediária.

Palavras-chave: redes, sociedade civil, ONGs, articuladoras, movimentos sociais

\section{Abstract}

Despite the notable political and analytical popularity of the concept of "civil society" in recent years, we know surprisingly little about the modus operandi of real civil organizations, even those that have been highlighted constantly in the literature because of their unprecedented leading role. Against this backdrop and using network analysis which was applied to the result of a survey of 202 civil organizations in the city of São Paulo, this article identifies the main leading actors within civil society and above all their different logics of performance and the dynamics of interaction amongst them. Our findings showed, as one would expect from the literature, that the NGOs comprise the group of actors with the greatest capacity for action within the network; however, little or no attention has been paid to the coordinating bodies which the research reveals as a recent innovation in the creation of collective actors-an innovation which has been notably successful. Moreover, the social movements emerged as the most central actors in the network, despite the supposed loss of their

\footnotetext{
${ }^{1}$ Adrian Gurza Lavalle - layda@usp.br. Graziela Castello - grazielacastello@yahoo.com.br. Renata Mirandola Bichir - renatambichir@yahoo.com.br
} 
leading role as has been diagnosed and taken for granted in the literature since the 1990 's. The three types of actors accumulate different structural advantages within the universe of civil organizations; they fulfill different roles and differ in importance to civil organizations that are peripheral or of intermediate centrality in the network.

Key words: networks, civil society, NGOs, coordinating bodies, social movements

\section{I ntrodução}

A extraordinária atenção suscitada pela sociedade civil no mundo acadêmico e nos circuitos nacionais e internacionais de formuladores de políticas públicas contribuiu, paradoxalmente, a eclipsar as organizações civis reais, sua diversidade, lógicas de atuação e dinâmicas de interação com outros atores. Nas últimas duas décadas, inúmeros esforços se empenharam em desbravar o terreno analítico para conferir precisão conceitual à categoria "sociedade civil", investindo-a, a um tempo só, de estatuto político normativo capaz de centrá-la como peça chave de novo projeto para "democratizar a democracia". ${ }^{2}$ Por motivos outros, nem sempre compatíveis com o propósito de reformar substantivamente a democracia, múltiplos atores multilaterais, governamentais e societários também granjearam, nesses anos, novo estatuto para a chamada sociedade civil, agora portadora inconteste de virtualidades positivas para o gerenciamento local e focalizado de políticas públicas, e para impulsionar a boa governança (UNDP 2002; World Bank 2001, 1997). Independentemente do mérito de tais esforços, sem dúvida foram bem-sucedidos se julgados pelos seus efeitos de proliferação: a literatura acadêmica centrada na sociedade civil é hoje quase incomensurável; as transferências financeiras de organismos multilaterais, governos e agências financiadoras do hemisfério norte para organizações não-governamentais do hemisfério sul aumentaram em proporções galopantes; ${ }^{3}$ isso sem esquecer, é claro, as inovações institucionais participativas que, no Brasil e pelo mundo afora, têm

\footnotetext{
${ }^{2}$ Cohen e Arato (1995) realizaram o esforço mais sistemático e abrangente de reconstrução teórica da categoria "sociedade civil", visando Ihe restituir o potencial heurístico e prático de transformação social. Por sua vez, diferentes autores orientados para o aprimoramento qualitativo da democracia ("democratização da democracia") compartilham a centralidade da categoria sociedade civil nos seus trabalhos (Santos Boaventura 2002, 1998; Avritzer 2003; Fung e Writ 2003; Heller, no prelo). A reconstrução da categoria acabou por lhe conferir feições distintivas e irreconciliáveis com as famílias pretéritas de argumentos da sociedade civil (Gurza Lavalle 1999).

3 Entre 1970 e 1990, as contribuições privadas e governamentais transferidas mediante as ONGs do hemisfério norte a suas homólogas do hemisfério sul aumentaram significativamente, passando de 1000 a 7.200 milhões de dólares. De fato, no início da década de 90,13\% das contribuições oficiais do hemisfério norte para o hemisfério sul eram alocadas por intermediação das ONGs (PNUD, 1993: 100 e 106).
} 
estimulado a intervenção de organizações civis no desenho e implementação de políticas públicas.

Porém, malgrado e em boa medida graças a semelhante sucesso, sabe-se surpreendentemente pouco acerca do modus operandi das organizações civis reais, mesmo daquelas que têm sido constantemente salientadas na literatura devido à emergência de protagonismos inéditos. Embora seja compreensível a presença rala na literatura de atores "miúdos", ora por seu perfil acanhado, ora por carecerem de implicações atraentes quando olhados das lentes das teorias, espanta a ausência de conhecimento sistemático e cumulativo sobre o funcionamento real de atores "graúdos" - inclusive no caso de organizações civis como as ONGs, consensualmente assinaladas na literatura como grande protagonista dos anos 1990. Com efeito, caracterizações altamente estilizadas de uma esfera de ação societária circunscrita por princípios unificadores comuns e por nítida diferenciação em relação ao Estado e ao mercado alimentaram consensos largamente difundidos sobre as potencialidades da sociedade civil - por sinal, consensos pouco sensíveis às diferenças internas, conflitos, afinidades, hierarquias e modalidades de articulação próprias ao universo das organizações civis reais.

Contra esse pano de fundo, este artigo visa trazer à tona e avançar na apuração de uma questão que, a despeito da sua relevância, tem recebido tratamento precário na literatura: como funcionam as organizações civis? Isto é, quais as diferentes lógicas de atuação e dinâmicas internas de interação que organizam o universo desses atores societários, particularmente daqueles que têm se notabilizado nos últimos anos pela seu protagonismo ou capacidade de atuação? Trata-se de avançar na elaboração de respostas alicerçadas na produção de conhecimento empírico, pelo que a própria definição dos atores com maior capacidade de atuação constitui um resultado empírico, evitando-se assim deduzir protagonismos a partir da literatura. Nesse sentido, aqui a idéia de "sociedade civil" permanece reservada apenas para remeter àquela perspectiva geral e estilizada existente na literatura, com ecos claros nas comunidades internacionais de formuladores de políticas, mas nunca aos atores empíricos estudados. Para eles utiliza-se o termo "organizações civis", mais neutro e, de certo, menos estilizado e normativamente sobrecarregado. ${ }^{4}$

\footnotetext{
${ }^{4}$ Dois componentes normativos definem as fronteiras da sociedade civil na literatura, a saber, autolimitação e autonomia dos atores societários (ver Cohen e Arato 1995; Olvera 2003). Não se sustenta nestas páginas
} 
O equacionamento das interrogações formuladas acima, de modo a torná-las passíveis de tratamento empírico sistemático, exige iniludivelmente um recorte sobre o mundo a ser observado. A partir de estratégia de análise de redes aplicada aos resultados de survey realizado na cidade de São Paulo em 2002, o funcionamento das organizações civis com maiores capacidades de atuação ou mais centrais será aqui reconstruído mediante três recortes analíticos: i) o papel desempenhado por diferentes tipos de entidades em relação ao universo das organizações civis; ii) as formas de relacionamento que as organizações civis de cada tipo estabelecem entre si, quer dizer, com outras entidades do mesmo tipo - ONGs com ONGs, organizações populares com organizações populares, etc -; iii) e os vínculos preferenciais que estruturam o universo dos atores estudados. Cada recorte é nutrido por uma mudança de ângulo ou perspectiva sobre a mesma unidade de análise: as relações. As vantagens cognitivas de se utilizar análise de redes para abordar conjuntos de atores normalmente encobertos pela categoria sociedade civil são conhecidas e têm recebido atenção alhures (Gurza Lavalle, Castello e Bichir 2006c). ${ }^{5}$

Os ganhos cognitivos possibilitados pela estratégia de análise de redes falam por si próprios. Como seria de se esperar a partir daquilo que tem sido apontado insistentemente na literatura, as ONGs compõem o elenco dos atores mais centrais na rede; entretanto, pouca ou nenhuma atenção tem sido prestada às articuladoras, reveladas pela pesquisa como uma inovação recente na criação de atores coletivos novação, por sinal, extraordinariamente bem sucedida. Ademais, os movimentos sociais (organizações populares) emergiram na pesquisa como os atores mais centrais da rede, a despeito da sua suposta perda de protagonismo, diagnosticada e tida como certa na literatura a partir dos anos 1990.

Os três recortes analíticos adotados revelaram padrões de relacionamento com conseqüências pertinentes para entender o funcionamento das organizações civis. Primeiro, trata-se de um universo de atores altamente hierarquizado, em que Organizações Populares, ONGs e articuladoras ocupam posições centrais privilegiadas por maiores capacidades de ação e escolha. Alhures (Gurza Lavalle, Castello e Bichir 2006c) foi mostrado que associações de bairro e comunitárias são claramente

qualquer crítica geral ao papel da teoria na construção de conhecimento, apenas atenta-se para os custos cognitivos de certas formulações teóricas da chamada sociedade civil de caráter normativo.

${ }^{5}$ Para um exame autorizado das vantagens analíticas da análise de redes no estudo dos movimentos sociais, ver o volume organizado por Diani e McAdam (2003). 
periféricas, acusando forte dependência das primeiras e com opções de atuação limitadas, enquanto os fóruns e as entidades assistenciais situam-se em posição intermediária. Segundo, os tipos de organizações civis melhor articuladas entre si, quer dizer, que utilizam a construção de vínculos com seus pares como estratégia de atuação (articuladoras com articuladoras, por exemplo), correspondem, precisamente, àquelas que também ocupam posições privilegiadas na rede como um todo. Por outras palavras, entidades periféricas entabulam poucas interações com entidades do mesmo tipo, o que aponta para a conexão entre a centralidade e capacidade de ação de cada tipo de organização civil e sua estratégia de atuação em relação aos seus pares. Terceiro achado: verificou-se a existência de vínculos preferenciais entre certos tipos de organização. Tais vínculos seguem sempre a mesma direção: das entidades periféricas para aquelas com maiores alcances e capacidade de atuação e, como era de se esperar, das organizações com posições privilegiadas para outras organizações igualmente privilegiadas.

Porém, entidades podem ocupar posições privilegiadas ou ter capacidades de atuação limitadas por diversos motivos e desempenhando papéis muito diferentes. É neste terreno que os resultados são mais valiosos, pois permitem caracterização relacional do funcionamento das organizações civis estudadas. Análises detalhadas desse funcionamento exigem espaço maior que o utilizado nestas páginas e, sem dúvida, seriam passíveis de elaboração em melhores condições dentro de artigos específicos. Aqui serão salientados apenas os principais achados contra-intuitivos e as feições mais relevantes do funcionamento dos tipos de organização civil mais centrais, de modo a atentar para lacunas no estado do conhecimento sobre os atores estudados - lacunas iluminadas ou "descobertas" a partir de uma perspectiva relacional. Dentre tais achados contra-intuitivos, cumpre por ora ressaltar apenas uma questão: as articuladoras desempenham um papel mais relevante na representação de interesses e na coordenação da atuação das organizações civis na cidade de São Paulo do que as organizações populares e do que as ONGs; o que aponta para mudanças importantes na lógica da ação coletiva apenas parcialmente registradas na literatura - a começar pelo fato de as articuladoras não terem sido objeto de estudo específico.

Os resultados apresentados, na íntegra, são produto de survey levado a cabo no município de São Paulo, ao longo de seis messes de trabalho de campo no ano de 2002. Os critérios de escolha, expostos em seção específica deste paper, favoreceram 
organizações civis ativas, particularmente aquelas engajadas nos segmentos malaquinhoados da população. Utilizou-se a técnica de bola-de-neve (snowball) para a construção da amostra e levantaram-se informações acerca das conexões ascendentes, descendentes e horizontais das entidades entrevistadas. ${ }^{6}$ Os diversos tipos de atores e o conhecimento estabelecido na literatura sobre eles serão abordados nas próximas seções, e, depois, serão explicitadas a estratégia de análise de redes aqui ensejada e a metodologia correspondente. Breve síntese dos resultados gerais em termos de posições centrais e marginais ocupadas pelas organizações civis, seguida do exame e interpretação detalhados das diferentes modalidades de protagonismo inerentes aos atores centrais analisados, ocuparão as penúltimas seções. $O$ artigo encerra com breve comentário final.

\section{Atores Centrais, porém Elusivos}

O estudo impõe o desafio de identificar e desenvolver caracterizações coerentes de organizações civis distinguidas por sua capacidade de atuação. Os rótulos normalmente utilizados para distinguir atores societários, todavia, são objeto de disputa simbólica para atribuir sentido a seu agir, e, portanto, a assunção de uma determinada denominação por parte das entidades entrevistadas obedece a uma série de cálculos de auto-apresentação pública, destinados a posicioná-las em campos específicos do mundo das organizações civis perante interlocutores determinados. No intuito de contornar essa dificuldade, as organizações civis não foram classificadas com base em suas autodefinições, senão conforme critérios objetivos de duas ordens: a relação com seus beneficiários e o perfil das atividades normalmente realizadas. No primeiro caso, (i) o conjunto dos beneficiários encarna uma unidade real ou abstrata (por exemplo, os moradores do bairro ou os cidadãos, respectivamente), (ii) cujos componentes são indivíduos, organizações e atores coletivos, ou segmentos da população (iii) concebidos como membros ou sócios, como público alvo, ou como a

\footnotetext{
${ }^{6}$ Também foram indagados as atividades, objetivos, origens e perfil institucional das organizações civis. Neste paper, além das características contempladas para a delimitação dos diferentes tipos de organizações civis (ver Quadro 1), apenas os vínculos receberam tratamento sistemático; entretanto, achados relevantes sobre atributos das organizações civis paulistanas têm sido aventados alhures (Houtzager, Gurza Lavalle e Acharya 2004; Gurza Lavalle, Houtzager e Acharya 2004b, Gurza Lavalle, Houtzager e Castello 2006a; 2006b). Os resultados apresentados nestas páginas formam parte de projeto de pesquisa mais amplo, cuja formulação por extenso, critérios metodológicos, bem como questionários e diferentes publicações dele derivadas encontram-se gratuitamente disponíveis na página eletrônica do próprio projeto (Houtzager, Harris, Collier e Gurza Lavalle 2002; Houtzager, Gurza Lavalle e Acharya 2003): "Rights, Representation and the Poor: Comparing Large Developing Country Democracies - Brazil, Indian and Mexico"http://www.ids.ac.uk/gdr/cfs/research/Collective\%20Actors.html
} 
comunidade. No segundo caso, a cada tipo de associação corresponde (i) uma estratégia de atuação distintiva e (ii) combinações excludentes de atividades orientadas para a reivindicação e mobilização, para o fornecimento de serviços, para a organização popular, ou para a intermediação entre o governo e os beneficiários.

Mediante a aplicação desses critérios tornou-se possível delinear uma tipologia de atores notabilizados por seu protagonismo dentro do universo das organizações civis, cujas feições tornam-se intuitivamente claras pelas denominações aqui utilizadas: organizações populares, articuladoras. Por exemplo, as ONGs costumam trabalhar para beneficiários definidos em termos de uma unidade abstrata (i), composta por determinados recortes ou segmentos da população (ii) concebidos não como membros ou sócios, mas como público alvo (iii) — v. gr. crianças vítimas de violência familiar -; sua estratégia de atuação distintiva normalmente é a tematização pública de problemas trabalhados dentro de uma semântica política de direitos cidadãos e/o humanos - direitos da criança e do adolescente - (i); nesse sentido, é raro definirem o perfil das suas atividades a partir da mobilização dos eventuais beneficiários ou da organização popular; antes, centram-nas em combinações diferentes de prestação de serviços e de intermediação simbólica ou material entre o poder público e a sociedade (ii).

Cumpre esclarecer que, dado o caráter empírico da tipologia, outros tipos de organizações civis foram encontrados, mas em virtude da sua posição periférica na rede não receberão tratamento nestas páginas. Contudo, a categoria "Demais Atores" não é residual: de um lado, adiciona os resultados, separadamente calculados, de quatro tipos de organizações civis definidos empiricamente conforme os mesmos critérios, e cujas posições na rede revelaram-se intermediárias ou francamente periféricas; de outro, funcionará como categoria de referência na ordenação dos dados a serem examinados nos primeiros dois recortes analíticos. Fóruns, entidades assistenciais, associações de bairro e associações comunitárias são assim grupadas sob a mesma rubrica não devido aos seus resultados individuais, mas porque a análise agregada mostrou se tratar de tipos de atores claramente diferenciados em relação às organizações civis centrais. ${ }^{7}$

\footnotetext{
7 Para uma exposição detalhada da tipologia expandida, bem como dos resultados da análise de redes para cada tipo de organização civil e do estado do conhecimento na literatura ver Gurza Lavalle, Castello e Bichir (2006c). Aqui cabe apenas fornecer definição sintética dos tipos de entidades que não são objeto deste artigo. Fóruns são espaços de encontro e adensamento de agendas temáticas para orientar a atuação de organizações civis. Entidades assistenciais trabalham prestando serviços diretos a terceiros, concebidos
} 
A relação entre a tipologia e as caracterizações disponíveis na literatura será abordada na próxima seção. O Quadro 1 sistematiza a tipologia, informa a freqüência relativa de cada tipo, oferece exemplos das organizações civis classificadas, e expõe outras informações úteis. A composição da amostra obedece aos critérios adotados para delimitar e recortar, conforme os propósitos da pesquisa, o universo de organizações civis entrevistáveis gerado pela técnica de bola de neve (snowball) (ver seção 4 acerca da estratégia analítica).

\begin{tabular}{|c|c|c|c|c|c|}
\hline Categoria & Freq & $\%$ & Beneficiários & Atividades & Exemplos \\
\hline $\begin{array}{l}\text { Organizações } \\
\text { Populares }\end{array}$ & 11 & 5 & $\begin{array}{l}\text { (i) Unidade } \\
\text { Abstrata } \\
\text { (ii) Segmentos da } \\
\text { população } \\
\text { (iii) Membros ou } \\
\text { Comunidade } \\
\end{array}$ & $\begin{array}{l}\text { (i) Articular atores e } \\
\text { iniciativas sociais } \\
\text { (ii) Reivindicação/ } \\
\text { mobilização; } \\
\text { intermediação }\end{array}$ & $\begin{array}{l}\text { MST; Movimento } \\
\text { de Moradia do } \\
\text { Centro; } \\
\text { Unificação de } \\
\text { Lutas de } \\
\text { Cortiços }\end{array}$ \\
\hline Articuladoras & 33 & 16 & $\begin{array}{l}\text { (i) Unidade Real } \\
\text { (ii) Organizações } \\
\text { e Atores } \\
\text { Coletivos } \\
\text { (iii) Membros }\end{array}$ & $\begin{array}{l}\text { (i) Articular atores e } \\
\text { iniciativas sociais } \\
\text { (ii) Reivindicação/ } \\
\text { mobilização; organização } \\
\text { popular; intermediação }\end{array}$ & $\begin{array}{l}\text { Ass. Brasileira } \\
\text { de ONGs } \\
\text { (Abong); } \\
\text { Fundação } \\
\text { Abrinq; Rede } \\
\text { Brasileira das } \\
\text { Entidades } \\
\text { Assisten-ciais } \\
\text { Filantrópicas } \\
\text { (Rebraf) }\end{array}$ \\
\hline ONGs & 60 & 30 & $\begin{array}{l}\text { (i) Unidade } \\
\text { Abstrata } \\
\text { (ii) Segmentos da } \\
\text { população } \\
\text { (iii) Público Alvo } \\
\end{array}$ & $\begin{array}{l}\text { (i) Tematizar publicamente } \\
\text { problemas } \\
\text { (ii) Reivindicação; } \\
\text { intermediação }\end{array}$ & $\begin{array}{l}\text { Instituto Polis; } \\
\text { Ação Educativa; } \\
\text { Grupo Corsa }\end{array}$ \\
\hline $\begin{array}{l}\text { Demais } \\
\text { Atores }\end{array}$ & 64 & 32 & - & - & $\begin{array}{l}\text { Fóruns, } \\
\text { entidades } \\
\text { assistenciais, } \\
\text { associações de } \\
\text { bairro e } \\
\text { comunitárias }\end{array}$ \\
\hline
\end{tabular}

Quadro 1. Tipologia de organizações Civis Centrais

Visto que toda tipologia leva à reagrupação de resultados em subconjuntos, caberia perguntar se eventuais agrupações seguindo outros critérios autorizariam leituras como aquela que será apresentada nestas páginas. A redução de casos (organizações civis) a clusters (tipologia) costuma obedecer a dois critérios básicos: ou há boas razões analíticas para optar por uma forma específica de agrupação ou análises

como públicos alvo a partir de critérios de vulnerabilidade. Associações de bairro são atores com identidade territorial voltados para a projeção de demandas ao poder público a respeito de infra-estrutura urbana. Associações comunitárias trabalham para os próprios membros da associação seguindo a lógica das associações mutualistas ou de ajuda mútua, e constituem nichos de convivência específicos (centro da juventude, clubes de idosos, de jogadores de bocha, etc). 
empíricas mediante técnicas de cluster mostram padrões empíricos consistentes independentemente deles corresponderem ou não a expectativas analíticas claramente formuladas. Neste caso, a agrupação responde a ambos critérios. De um lado, a tipologia de organizações civis constitui uma síntese do conhecimento acumulado sobre esse universo de atores e agiliza a interlocução com atores e autores interessados nas questões aqui analisadas; do outro, testes empíricos não revelaram outras formas de agrupação consistentes.

\section{A Literatura e as Caracterizações}

A distância entre a tipologia e as caracterizações existentes na literatura é menor no caso dos atores que maior atenção têm recebido, tal e como ocorre com as ONGs. Embora a denominação "organização não-governamental", oriunda dos organismos de cooperação internacional, tenha sido utilizada de modo corrente como termo genérico na literatura internacional, no Brasil corresponde strictu sensu às organizações civis conhecidas na literatura anglo-saxônica como entidades de Advocacy — dedicadas a vocalizar ou reivindicar publicamente as demandas e necessidades de terceiros, quer dizer, de determinados segmentos da população ou de determinadas causas. Se na sua origem foram concebidas como entidades de assessoria aos movimentos sociais, avessas a qualquer protagonismo próprio, há consenso amplo na literatura nacional quanto ao fato de as ONGs terem se tornado os atores de maior destaque no cenário da ação coletiva nos anos $1990 .^{8}$ Também há consenso no que diz respeito a certas feições recorrentes na sua caracterização, a saber, discurso elaborado dentro de uma semântica de direitos e de ampliação substantiva da democracia, orientação temática, ação voltada à publicitação de problemas, e coordenação com outros atores mediante trabalho em rede; por outras palavras, as ONGs apresentam "... forte vocação para uma atuação no campo da política, o investimento na mobilização da opinião pública, no lobby, na defesa no espaço público de interesses difusos... esse tipo de atuação pressupõe o desenvolvimento da habilidade, por parte das ONGs, em estabelecer interações, parcerias, formas de comunicação e cooperação ... [de modo a desempenhar] seu tradicional papel de multi-mediadoras sociais" (Landim 1996: xiv). ${ }^{9}$

\footnotetext{
${ }^{8}$ V.gr: "... as ONGs passaram a ter muito mais importância nos anos 90 do que os próprios movimentos sociais" (Gohn 2003: 22; ver também Paz 2005: 8-11).

9 Na caracterização de Maria do Carmo Carvalho (1998: 87-88), as ONGs se regem pelo princípio da solidariedade, por ações de multiple advocacy, de empowerment, e determinam fortemente a agenda
} 
A definição de para quem trabalham as ONGs é menos pacífica na literatura, pois mesmo se aceita essa função de mediação capaz de transitar "entre os locais românticos das comunidades tradicionais e os esclarecidos territórios da cidadania" (Fernandes 2002: 76), ou sua conhecida origem como entidades de apoio aos movimentos populares, ${ }^{10}$ parece inescapável reconhecer que "tal função de mediação é unilateral" (Fernandes 2002: 78). A compreensão dos beneficiários do trabalho dessas organizações em termos de público alvo, a despeito de parcialmente controversa, aponta precisamente para essa unilateralidade. ${ }^{11}$

Uma segunda categoria da tipologia também tem sido amplamente estudada, embora sob denominação diferente. "Organizações populares" correspondem em parte àqueles atores que, a partir dos anos 1970 e, sobretudo, nos 1980, passaram a ser denominados e pensados nos registros teóricos desenvolvidos em torno do conceito "movimentos sociais" - especialmente quando utilizado para apreender a lógica de atuação de atores específicos voltados para a mobilização coletiva a propósito de demandas populares. À margem das orientações teóricas mais influentes na literatura sobre movimentos sociais ${ }^{12}$, o conceito apresenta problemas de ambigüidade na sua definição: tem sido utilizado igualmente na definição de atores empíricos específicos, normalmente portadores de capacidade de contestação perante o Estado - Movimento dos Sem Terra (MST), Movimento dos Atingidos por Barragens (MAB) -, e na unificação analítica de conjuntos esparsos de iniciativas individuais e coletivas

pública. A importância das redes ou a caracterização do estilo de trabalho das ONGs com base na noção de redes é constante na literatura (Fernandes 1994: 128-131; Scherer-Warren 1996).

10 Há quem ainda descreva a relação entre as ONGs e seus beneficiários em termos que parecem mais apropriados para as décadas de 1970 e 1980: "... na maior parte [trabalhando] junto a grupos populares discriminados ou marginalizados..." (Gohn, Ilse In: Coelho 2000: xv). Também: até há alguns anos e pelas prioridades das agências financiadoras "... a razão de ser de muitas ONGs estava associada a sua aliança com organizações populares". (Casanovas e García 1999: 63-67) Ver o trabalho de Landim (2002) para uma reconstrução notável da gênese das ONGs como entidades de assessoria e apóio nos anos setentas, e sua diversificação temática e adensamento organizativo na forma de sub-redes, o que teria levado essas entidades - em processo tortuoso - a assumir para si a identidade de ONGs e a se desvencilhar progressivamente do seu arraigo (e in-diferenciação) nos atores populares. A mesma autora afirma, no entanto, que o contato com grupos populares continua a ser relevante para as ONGs (Landim 1998).

${ }^{11}$ É possível, ainda, encontrar especificações dos beneficiários do trabalho das ONGs em registro semelhante ao da assistência, próprio de entidades beneficentes (ver Coelho 2000: 60).

12 Houve três grandes vertentes na literatura internacional sobre os movimentos sociais: abordagens estruturalistas que privilegiaram o movimento urbano popular (Castells 1988; Borja 1981; Singer e Brant 1980); abordagens pós-estruturalistas centradas nos processos de construção das identidades dos chamados novos movimentos sociais (Evers 1984; Melucci 1989; Touraine 1983; Sader 1988); e as abordagens estratégicas do debate anglo-saxônico, que atentaram para as capacidades e dilemas da mobilização de recursos (Klandermans e Tarrow 1988). Para um balaço acessível das três perspectivas ver Gohn (1997). As duas primeiras abordagens tornaram-se dominantes no Brasil, por vezes em combinações inovadoras de notável riqueza sociológica (ver Sader 1988). 
sintonizadas ao longo do tempo por afinidades de sentido em torno de temas específicos - movimento feminista, movimento negro, movimento de moradia, movimento de saúde. O universo de atores aqui definidos como organizações populares corresponde à primeira acepção. Salvo raras exceções (v. gr. Feltran 2005; Mendonça 2002; Marteleto, Ribeiro e Guimarães 2002), os movimentos sociais registraram misterioso sumiço na literatura a partir do início dos anos 1990, em boa medida graças ao encerramento do ciclo da transição e à conseqüente estabilização e institucionalização da política e do protesto social, mas também devido a mudanças nas categorias analíticas utilizadas - agora convertidas ao registro heurístico da sociedade civil e/ou das ONGs (Gurza Lavalle, Castello e Bichir 2004a; Sobottka 2002). A onda de balanços desiludidos do final dos anos 1980, apontando para a desmobilização e cooptação dos atores, bem como para a ingenuidade e otimismo dos autores, parece ter prenunciado um certo abandono do conceito. ${ }^{13}$ De fato, em que pesem os diagnósticos sobre os efeitos cognitivamente deletérios da relação "ciclotímica" entre o pensamento acadêmico e a ação coletiva (Götz 1995), não é raro se deparar ainda hoje com diagnósticos que reafirmam o esmaecimento dos movimentos e a despolitização generalizada da ação coletiva - agora concentrada em demandas de mera sobrevivência material ou correções de caráter pontual —, imputando semelhante panorama aos efeitos corrosivos do ajuste estrutural ( $\mathrm{v}$. gr. Casanovas e García 1999: 63-67; Rucht 2002). ${ }^{14}$ Seja como for, aos movimentos sociais foi e é conferida uma capacidade de ação coletiva centrada na construção de novas identidades, normalmente não absorvíveis dentro do universo das instituições tradicionais de representação interesses; também um protagonismo altamente espontâneo, devido à exigência de uma mobilização não burocratizada ou corporativizada.

Embora as entidades denominadas como articuladoras na tipologia ocupem novo espaço no cenário da ação coletiva institucionalizada, não têm recebido atenção na literatura ou, com maior precisão, é regra serem rotuladas como ONGs — e em menor medida como Organizações Populares - e tratadas assim de modo indiferenciado sob

\footnotetext{
${ }^{13}$ Ver, por exemplo, os balanços desenvolvidos por Ruth Corrêa Leite Cardoso (1994: 81-90), Flávio S. Cunha, (1993: 134-135) e Edison Nunes (1987: 92-94).

14 Segundo Gohn (2003: 13-32), por exemplo, nos anos 1990 não há processos de mobilização de massa, mas de mobilização pontual dentro da lógica da participação cidadã, e não do ativismo popular coletivo.
} 
essa rubrica ${ }^{15}$. O empenho das ONGs na criação de redes e de espaços de coordenação é amplamente reconhecido (v. gr. Casanovas e García 1999: 69-74; Scherer-Warrem 1996), todavia, articuladoras diferem significativamente das ONGs em aspectos relevantes para análises preocupadas com a compreensão das dinâmicas e padrões de interação que ordenam o universo das organizações civis. Isto, em virtude de serem fundadas por outras entidades com o intuito de coordenar e articular suas ações, de construir agendas comuns e de escalar sua capacidade de agregação de interesses com fins de representação perante o poder público e outros atores sociais. Por outras palavras, as articuladoras podem ser classificadas como organizações civis de terceira ordem, quer dizer, distintas tanto daquelas instituídas sob o signo da identidade entre beneficiários e fundadores, administradores ou trabalhadores das associações organizações civis de primeira ordem como as associações de bairro ou as de caráter comunitário -, quanto daquelas outras estabelecidas para beneficiar terceiros definidos como pessoas ou segmentos da população - nesse sentido, de segunda ordem, como as entidades assistenciais e as ONGs.

\section{Centralidade, Análise de Redes e Survey}

A análise de redes sociais assume como premissa a importância dos laços sociais como elementos que estruturam a vida social, imputando a eles diversas conseqüências em termos de possibilidades e restrições para a ação de indivíduos e atores coletivos. A unidade de análise utilizada são as relações estabelecidas entre pessoas e entre entidades, e não os indivíduos ou organizações em si e sequer seus atributos. Como estratégia analítica, situa-se em plano cognitivo intermediário, trazendo consigo mudanças de perspectiva tanto na compreensão do plano macro quanto do micro (Emirbayer 1997). No plano macro (v.gr. sociedade/sociedade civil), evitam-se interpretações centradas em "esferas" ou "sistemas" autônomos, internamente organizados e auto-sustentáveis; no entanto, atenta-se para as múltiplas redes de interação social que compõem esse plano, sobrepondo-se de modo complexo. No plano micro (v.gr. indivíduos/organizações civis), os atores não são tomados como entidades

\footnotetext{
${ }^{15}$ Da mesma forma em que boa parte das articuladoras são pensadas como Ongs, algumas poderiam ser assimiladas às organizações populares; porém, a atuação dessas entidades na coordenação e representação de interesses de outras organizações civis, e não voltada para mobilização direta de segmentos da população, valida a distinção. De modo emblemático, todas as articuladoras de movimentos sociais contempladas na amostra analisada aqui nasceram após o contexto de transição: Central de Movimentos Populares (fundada em 1993), Fórun dos Mutirões de São Paulo (1992), União dos Movimentos de Moradia (1987) e Associação dos Movimentos de Moradia da Região Sul (1994).
} 
pré-constituídas e bem definidas; ao contrário, destaca-se que a formação dos próprios atores e suas capacidades ocorre por meio de interações complexas. É importante destacar que, a rigor, a análise de redes sociais não constitui uma teoria e tampouco um conjunto de técnicas estatísticas complexas, mas uma estratégia analítica passível de utilização à luz de diferentes perspectivas conceituais e teóricas. ${ }^{16}$

Assume-se aqui que o protagonismo das organizações civis é expressão de sua capacidade de atuação. Na análise de redes, tal capacidade depende do posicionamento do ator numa teia de relações que independe da sua vontade ou com, maior precisão, depende da sua centralidade na rede; os vínculos podem até ser lançados de forma intencional, mas a posição no conjunto é não pode ser deduzida inteiramente, ainda mais no caso de redes complexas. Um ator central no interior de uma dada rede é aquele que, a partir de um número considerável de relações, consegue exercer grande influência sobre os demais atores e gerar neles certa dependência, controlando diversas possibilidades de fluxos e desfrutando uma capacidade maior de fazer escolhas dentro de seu universo de relações (Hanneman 2001). Enquanto as escolhas aparecem associadas à capacidade de ação ou agência, os fluxos remetem a bens materiais e imateriais, cuja natureza varia enormemente dependendo dos atores contemplados pela análise; por exemplo, dinheiro, mercadorias ou coisas no primeiro caso, e informações, influência ou afeto, no segundo. Ademais, atores centrais ocupam posições estratégicas no interior da rede, sendo importante considerar não apenas os vínculos diretos com outros atores, mas também aqueles de caráter indireto (Wasserman e Faust 1994). A centralidade no interior de uma rede surge como conseqüência dos padrões de relações estabelecidos entre os atores e, portanto, não é um atributo ou "posse" dos atores em si. ${ }^{17} \mathrm{Em}$ suma, a noção de centralidade está associada à noção de capacidade de ação, quer dizer, de escolha entre diversas alternativas possíveis e de autonomia - pouca ou nenhuma dependência - em relação aos vínculos estabelecidos com atores específicos.

\footnotetext{
${ }^{16}$ No Brasil trata-se de estratégia analítica de incipiente difusão. Os trabalhos de Marques (2000 e 2003) são pioneiros e constituem a referência mais relevante de aplicação bem-sucedida da análise de redes ao campo das políticas públicas.

${ }^{17}$ Conforme destaca Scott (1992), a centralidade de um ator não pode ser determinada isoladamente, sem a consideração da centralidade de todos os outros atores aos quais está conectado.
} 
Embora existam diversas ferramentas analíticas disponíveis no âmbito da metodologia de análise de redes, a maior parte dos resultados aqui expostos exprimem medidas de centralidade $^{18}$, utilizadas para destacar a posição relativa de cada um dos atores considerados, identificando, neste caso, posições claramente centrais dentro do universo das organizações civis. Grosso modo, na análise foram empregadas sete medidas. ${ }^{19}$ Procurou-se identificar tanto as organizações da sociedade civil que funcionam como referências ou detêm "prestígio" no conjunto das organizações, sendo muito citadas (número de vínculos recebidos - indegree), quanto aquelas caracterizadas por citar muitos parceiros (número de vínculos enviados - outdegree). ${ }^{20}$ Também foi analisada a relação entre tipos de organizações civis e suas capacidades de intermediação (betweeness) e articulação de diferentes sub-redes; capacidades que permitem, do ponto de vista do intermediário, impedir ou facilitar o contato entre diversas entidades, bem como controlar os fluxos entre elas. Outra forma de caracterização da centralidade consistiu na observação das organizações civis relativamente mais próximas das outras — proximidade (closenness) passível de ser traduzida em capacidade de ação e de coordenação. ${ }^{21}$ Examinou-se igualmente a assimetria das relações existentes entre as organizações civis, aferindo a dependência produzida por certas entidades sobre outras, ou o poder de determinada entidade (power). Procurou-se diferenciar, ainda, as organizações que lançam mais vínculos daquelas que são preponderantemente receptoras de vínculos, apresentando diferentes tipos de influência (influence). Procurou-se destacar, também, as organizações com maior acesso à informação (information) no interior da rede, isto é, ao controle de certos fluxos preferenciais entre o conjunto de relações disponíveis.

De uso mais modesto nesta análise, algumas medidas de coesão foram empregadas com o intuito de determinar o modo de estruturação dos atores e suas relações no interior de uma rede, abordando aspectos como o tamanho da rede, a densidade da rede, as distâncias existentes entre cada um dos atores (geodesic distance) e o número de atores que podem ser alcançados no interior da rede (reachability). ${ }^{22}$ Além

\footnotetext{
${ }^{18}$ Para uma discussão conceitual a respeito das medidas de centralidade e coesão utilizadas usualmente nas análises de redes sociais, ver Hanneman (2001).

${ }^{19}$ No processamento das medias foi utilizado o software Ucinet (Borgatti, Everett e Freeman 2002).

${ }^{20}$ Aqui se resolveu diferenciar a origem e o destino dos vínculos. Apenas no caso de algumas medidas, por motivos técnicos, as relações presentes na rede foram consideradas de modo simétrico. .

${ }^{21}$ Para um exame da proximidade como "vantagem estrutural" ver o trabalho de Hanneman (2001:65).

22 O tamanho da rede corresponde ao número total de atores e pode limitar significativamente a capacidade de construção e manutenção de vínculos, isto é, as interações possíveis. A densidade corresponde à
} 
disso, também foram utilizadas representações gráficas das redes — sociogramas ${ }^{23}$ tanto para introduzir subsídios de caráter mais qualitativo à análise quanto para tornar mais fácil a compreensão dos resultados mediante representações visuais peculiarmente elucidativas.

A despeito da índole altamente intuitiva das medidas de centralidade e coesão, sua expressão numérica parece complexa e carece de referentes empíricos óbvios. Optouse aqui por apresentar resultados simplificados. Para tanto, os resultados das medidas de redes para os atores centrais - apresentados em tabelas resumo — foram convertidos ou em porcentagens, sempre em relação à média dos Demais Atores na amostra - tomada como valor de referência -, ou em ranking simples. As denominações técnicas das medidas também foram simplificadas. É importante ressaltar que os padrões estruturais de inserção dos diferentes tipos de organizações civis na rede foram construídos após a análise integrada de todas as medidas geradas, e não com base em medidas isoladas - as quais carecem de sentido se consideradas de modo independente.

Todas as informações relacionais necessárias para análise de redes aqui apresentada foram obtidas por meio de entrevistas realizadas com 202 organizações civis, em pesquisa realizada no município de São Paulo em 2002. ${ }^{24}$ Ao todo, as entrevistas com essas 202 entidades geraram um total de 741 atores diferentes citados e 1.293 relações diretas levantadas. Na medida em que cada entidade entrevistada pôde citar até 5 relações em ordem de importância ou as mais próximas para diferentes tipos de entidades, as redes examinadas nestas páginas representam a malha mais densa de relações existentes entre as organizações civis paulistanas pesquisadas - não a totalidade de vínculos existentes. Cada relação direta incrementa exponencialmente o número de relações indiretas e, por isso, há um total de 549.081 relações possíveis. O

proporção de vínculos realmente existentes dentre o total de vínculos possíveis, sendo que ela tende a ser menor quanto maior o tamanho da rede. Além disso, de acordo com Hanneman (2001), redes com baixa densidade tendem a ter pouco poder - este tende a estar diluído entre os diversos atores. As distâncias também são importantes para caracterizar a rede como um todo. A menor distância possível entre dois atores é denominada distância geodésica.

23 Nos sociogramas cada ponto representa uma organização civil e os traços representam as relações existentes entre essas organizações. Os sociogramas são particularmente intuitivos e não requerem maiores explicações; entretanto, cumpre esclarecer que o comprimento das linhas e a representação visual da posição do ator no desenho são "arbitrários", isto é, não representam qualquer "distância" entre esses atores, mas apenas a presença ou ausência de vínculo.

${ }^{24}$ No trabalho de campo foram entrevistadas 229 organizações civis, mas devido a critérios metodológicos apenas foram contempladas 202 na análise de redes. 
universo das entidades pesquisadas não foi definido a priori, mas empiricamente como base nas cadeias de referências fornecidas, a partir de 16 pontos de entrada, pelos atores entrevistados; referências colhidas em campo por meio da técnica bola de neve (snowbal) - bastante utilizada em análises de redes sociais (Scott, 1992). ${ }^{25}$

\section{Padrões de relacionamento das organizações civis centrais}

Esta seção apresenta de modo sintético os principais resultados que permitem identificar os padrões de relações das organizações civis com maiores capacidades de atuação. A interpretação dos padrões encontrados será efetuada na seguinte seção, atentando para seu significado segundo o tipo de entidade considerado.

As relações foram examinadas a partir de três ângulos ou recortes analíticos. No primeiro caso, a distinção entre os papeis desenvolvidos pelos diferentes tipos de organizações civis exige centrar o foco na relação entre cada tipo e o universo das organizações como um todo; no segundo, é preciso fixar o olhar e examinar cuidadosamente apenas as conexões internas próprias a cada tipo de organização civil, como se se tratasse de esquadrinhar subcampos caracterizados por lógicas relacionais distintas; no terceiro, a atenção não se detém no universo das organizações civis como um todo, nem nas dinâmicas das organizações pertencentes ao mesmo tipo, mas opera novo recorte sobre as inter-relações mais freqüentes entre tipos de entidades distintos, mostrando claramente afinidades e distâncias que organizam as relações dos atores centrais no universo das organizações civis na cidade de São Paulo.

Cada recorte apresenta contribuições específicas para o entendimento das dinâmicas de funcionamento das organizações civis: o primeiro mostrou a estruturação altamente hierárquica desse universo de atores; o segundo revelou que as entidades com as redes mais coesas e organizadas entre si são, precisamente, aquelas que também ocupam posições centrais no conjunto das organizações civis - apontando, assim, uma conexão clara entre a centralidade de um tipo de organização civil e suas estratégias de atuação em relação às entidades do seu mesmo tipo; por fim, o terceiro ângulo evidenciou a existência de vínculos preferenciais entre certos tipos de

\footnotetext{
${ }^{25}$ São bem conhecidas as circunstâncias em que a técnica bola de neve oferece vantagens metodológicas (ver Atkinson e Flint 2003; Goodman 1961; Sudman e Kalton 1986). Para uma análise das vantagens de se utilizá-la especificamente no estudo de organizações civis ver Houtzager, Gurza Lavalle, Acharya (2004: 288-291), e Gurza Lavalle, Houtzager e Acharya (2005). Informações mais detalhadas sobre os critérios de construção da amostra mediante a bola e neve podem ser consultadas em Houtzager, Gurza Lavalle e Acharya (2003).
} 
organização; preferências que, antes de serem fortuitas ou casuais, indicam a sedimentação de padrões históricos de relacionamento.

\section{Organizações civis centrais em uma rede hierárquica}

O principal resultado a ser destacado, do ponto de vista da inserção das organizações civis na rede como um todo ${ }^{26}$ refere-se à marcada estratificação das diversas organizações civis. Há três tipos de entidades que ocupam posições altamente centrais, enquanto os demais atores se situam em posições periféricas ou intermediárias, acusando dependência em relação às primeiras. Os dados apresentados na Tabela I evidenciam o contraste; os números exprimem, para cada medida, a posição relativa dos tipos de organizações civis examinados em relação aos Demais Atores da amostra; isto é, o quanto (\%) os tipos mais centrais se aproximam ou afastam da média dos resultados médios dos tipos de entidade compreendidos nos Demais Atores. ${ }^{27}$ Assim, por exemplo, as articuladoras realizam $139 \%$ mais intermediação do que os Demais Atores (Tabela 1).

No "ápice" do universo das organizações civis se encontram as organizações populares, seguidas das articuladoras e das ONGs. Em decorrência de seus padrões de relações, essas entidades apresentam os melhores resultados em praticamente todas as medidas de centralidade, ou seja, ocupam posições mais centrais tanto pela quantidade de vínculos enviados e recebidos quanto pela sua capacidade de intermediação e de difusão de informação, e, no caso organizações populares e das articuladoras, também pelo balanço favorável entre as relações enviadas e recebidas (influência). Nesse balanço e na clara dependência gerada por ambos os tipos de organizações nas outras entidades (poder), percebe-se marcado contraste com o padrão de centralidade das ONGs - as quais não geram dependência nem recebem mais vínculos dos que enviam. ${ }^{28} \mathrm{~A}$ interpretação dos diferentes padrões de centralidade segundo cada um desses tipos de organizações civis mais centrais será efetuada na seguinte seção. No caso das medidas de coesão, bem como nos dados de

\footnotetext{
${ }^{26}$ Todos os vínculos levantados constituem, efetivamente, uma única rede o componente. Para uma análise das suas principais características, ver (Gurza Lavalle, Castello e Bichir 2006c).

27 Todas as medidas a serem apresentadas foram estimadas mediante a aplicação de diferentes ponderadores (normalizações) para controlar os efeitos decorrentes do peso dos distintos tipos de organização civil na amostra. Aqui são apresentadas apenas as porcentagens calculadas a partir das médias normalizadas e sempre em relação aos Demais Atores - categoria tomada como valor de referência. Ou seja, os valores são médias de médias.

${ }^{28}$ De fato, todos os tipos de organizações civis - inclusive os quatro tipos compreendidos nos Demais Atores - geram mais dependência do que as ONGs.
} 
proximidade, a variação geral dos resultados é muito menor, mas ainda assim as organizações em questão apresentam posições relativamente favoráveis. Em suma, os resultados apontam de modo consistente para o papel protagônico desses três tipos de entidades dentro do universo das organizações civis paulistanas - protagonismo que pode ser desempenhado ora na agregação de interesses, ora na coordenação da ação coletiva, ou na definição de referenciais simbólicos.

\begin{tabular}{|c|c|c|c|c|c|c|c|c|c|c|c|}
\hline \multirow[b]{2}{*}{$\begin{array}{l}\text { Tipologia de } \\
\text { Entidades }\end{array}$} & \multicolumn{8}{|c|}{ Centralidade (\%) } & \multicolumn{3}{|c|}{ Coesão (\%) } \\
\hline & 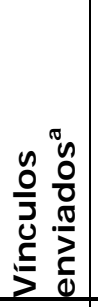 & 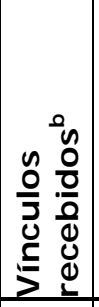 & 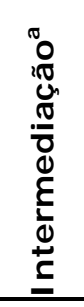 & 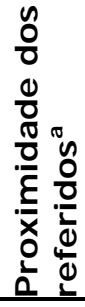 & 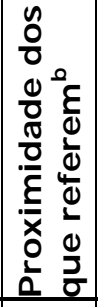 & 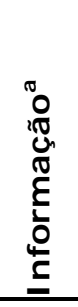 & $\begin{array}{l}\frac{\pi}{2} \\
\frac{0}{8} \\
\stackrel{0}{0} \\
\end{array}$ & 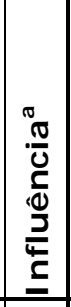 & 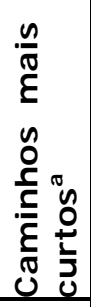 & 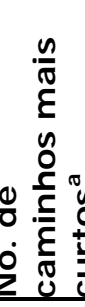 & 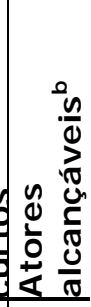 \\
\hline $\begin{array}{l}\text { Organizações } \\
\text { Populares }\end{array}$ & 33 & 266 & 240 & 6 & 3 & 37 & 31 & 131 & -8 & 13 & 20 \\
\hline Articuladoras & 34 & 85 & 139 & 4 & -1 & 12 & 21 & 35 & 2 & 1 & 2 \\
\hline ONGs & 66 & 41 & 66 & 4 & 14 & 13 & -113 & -98 & -16 & 13 & 27 \\
\hline Demais Atores $^{c}$ & & $* * *$ & $* * *$ & $* * *$ & $* * *$ & $* * *$ & $* * *$ & $\begin{array}{c}* * \\
*\end{array}$ & $* * *$ & $* * *$ & $* * *$ \\
\hline
\end{tabular}

Tabela I: Centralidade e coesão da rede segundo tipos de organizações civis $^{29}$

a Médias calculadas apenas para as entidades entrevistadas $(n=202)$

b Médias calculadas para toda amostra $(n=829)$

c Valor de referência: :média de médias, calculada a partir da adição das medidas para quatro tipos diferentes de organizações civis - fóruns, associações assistenciais, associações de bairro e comunitárias.

\section{Dinâmica interna dos tipos centrais de organizações civis}

O segundo recorte analítico foca as relações internas entre as organizações civis de cada tipo. A Tabela II resume as medidas calculadas para sub-redes definidas por tipo de organização civil, quer dizer, retirando-se as conexões com os outros tipos de entidade. De maneira geral, os resultados produzidos deste ângulo podem ser sumarizados nos seguintes termos: os tipos de organizações que ocupam posições centrais na rede como um todo também apresentam organicidade e complexidade desproporcionalmente maiores nas suas relações internas ou com entidades do mesmo tipo, tanto em termos de densidade (elevado número de vínculos) quanto em termos de intermediação ou do número de atores alcançáveis. Com cifras menos avultadas, a

\footnotetext{
${ }^{29}$ Para o cálculo das medidas foi considerada a direção das relações.
} 
coincidência entre a centralidade geral e a coesão e densidade internas também pode ser observada no caso das outras medidas. A rede interna das organizações populares é de longe a mais densa em termos do número de vínculos, aquela em que há mais intermediação interna - algumas organizações populares atuam como pontos de passagem necessários para todas as outras - , e em que os atores estão relativamente mais próximos entre si. Com redes consideravelmente maiores, obstando a proximidade interna, articuladoras e ONGs apresentam feições semelhantes, embora atenuadas. Cabe destacar que a ausência de dependência constitui traço complementar da maior organicidade e horizontalidade dos vínculos internos das organizações populares e das articuladoras; porém, diferentemente desses tipos de organizações civis, verifica-se significativa assimetria de poder ou dependência no caso das relações entre ONGs. O assunto será retomado na seção seguinte.

\begin{tabular}{|c|c|c|c|c|c|c|c|c|c|}
\hline \multirow[b]{2}{*}{$\begin{array}{l}\text { Tipologia de } \\
\text { Entidades }\end{array}$} & \multicolumn{6}{|c|}{ Centralidade $^{a}(\%)$} & \multicolumn{3}{|c|}{ Coesão $^{a}(\%)$} \\
\hline & 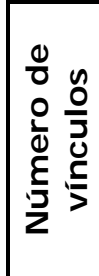 & 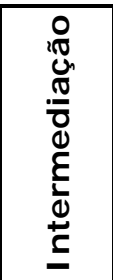 & $\begin{array}{l}\frac{0}{0} \\
\frac{\pi}{0} \\
\frac{0}{\varepsilon} \\
\frac{g}{x} \\
0 \\
\frac{0}{a}\end{array}$ & 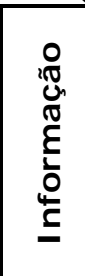 & $\begin{array}{l}\frac{1}{0} \\
\stackrel{0}{0} \\
0\end{array}$ & 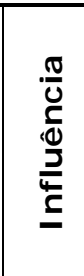 & 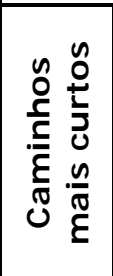 & 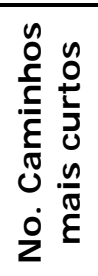 & 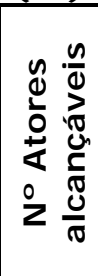 \\
\hline Organizações Populares $(n=20)$ & 1157 & 3659 & 572 & 21 & -654 & 35 & 21 & 8 & 868 \\
\hline Articuladoras $(n=104)$ & 84 & 1361 & 14 & 38 & -357 & 63 & -89 & 3 & 674 \\
\hline ONGs $(n=187)$ & 46 & 2076 & -14 & 80 & 59 & 128 & -171 & 56 & 1180 \\
\hline Demais Atores $^{\mathbf{b}}(n=140)$ & $* * *$ & $* * *$ & $* * *$ & $* * *$ & $* * *$ & $* * *$ & $* * *$ & $* * *$ & $* * *$ \\
\hline
\end{tabular}

Tabela II : Centralidade e coesão das redes internas de cada tipo de organização civil ${ }^{30}$

a Para o cálculo das médias foram consideradas todas as entidades presentes na amostra. Contudo, o tamanho das redes varia de acordo com o tipo de organização civil analisado.

b Valor de referência:media de médias, calculada a partir da adição das medidas para quatro tipos diferentes de organizações civis - fóruns, associações assistenciais, associações de bairro e comunitárias.

Em suma, o fato de os atores caracterizados pela posse das redes mais coesas e organizadas internamente corresponderem exatamente àqueles que ocupam posições mais centrais na rede como um todo apontam para uma estreita relação entre os modos de organização interna dos diferentes tipos de entidades - padrões de relação, grau de coesão e hierarquização interna — e os papéis por eles desempenhados no universo das organizações civis.

30 Por se tratar das medias internas de cada tipo, no cálculo das medidas não foi considerada a direção das relações., 


\section{Do centro ao centro e os demais ... também}

O terceiro recorte ilumina os vínculos preferenciais das organizações civis ao atentar para as relações estabelecidas não entre as entidades na rede como um todo, nem nas redes internas, mas entre tipos diferentes de organizações. A análise procede por meio do recorte das redes que unem tipos de organizações civis em pares, ou duas a duas - ONGs com articuladoras, ONGs com organizações populares e assim por diante -, de modo a verificar tanto os vínculos mais "valiosos" ou procurados por diversos atores quanto as relações mais "eficientes" em termos de ampliação da capacidade de atuação dos tipos de organizações nelas envolvidos. A Tabela III sumariza a lógica dos vínculos preferenciais. Foram considerados apenas os ganhos obtidos em cada um dos cruzamentos entre dois tipos de organizações civis, cancelando os resultados oriundos das redes internas; isto é, consideram-se apenas os saldos da interseção entre duas redes. A tabela apresenta, em primeiro lugar, o número de vínculos novos que surgiram nas redes para cada combinação em pares por tipos de organizações civis; em segundo lugar, o incremento na capacidade de intermediação oriunda das relações entre os tipos de entidades, ou seja, os ganhos de intermediação; já a terceira medida afere a integração ou grau de aproveitamento das relações hipoteticamente disponíveis graças ao cruzamento entre as redes de dois tipos de organização civil — por outras palavras, mostra o quanto das relações que potencialmente poderiam existir em cada cruzamento estão efetivamente presentes. Neste caso, os tipos compreendidos na categoria Demais Atores, na tipologia e nas tabelas precedentes, figuram de modo separado, ou seja, são apresentados individualmente e não de forma agregada. Os resultados são apenas um ranking simples que ordena, dos melhores aos piores resultados, cada uma das três medidas para cada tipo de ator central.

Como seria de se esperar, as entidades centrais não apenas cultivam vínculos preferenciais com atores igualmente centrais, mas desenvolvem entre si uma integração mais ampla - maior número de vínculos possíveis que estão efetivamente presentes. Assim, organizações populares encontram-se mais integradas ou aproveitam mais a potencialidade das relações que estabelecem com articuladoras e ONGs; articuladoras guardam maior integração com ONGs e organizações populares; e, por sua vez, ONGs com organizações populares e articuladoras. Embora em patamar inferior, também é possível apreciar certa relevância das relações entre organizações 
populares, articuladoras e ONGs, com atores de centralidade média como fóruns e entidades assistenciais.

\begin{tabular}{|c|c|c|c|c|c|c|c|c|}
\hline \multirow[b]{2}{*}{$\begin{array}{c}\text { Tipologia de } \\
\text { entidades }\end{array}$} & \multirow{2}{*}{$\begin{array}{l}\text { Ganhos da } \\
\text { Intersecção }\end{array}$} & \multicolumn{7}{|c|}{ Organizações com as quais se estabelecem as relações ${ }^{a}$} \\
\hline & & \begin{tabular}{|c|} 
Organizações \\
Populares
\end{tabular} & Articuladoras & ONGs & \begin{tabular}{|c|} 
Entidades \\
Assistenciais \\
\end{tabular} & Fóruns & \begin{tabular}{|c|} 
Ass. de \\
Bairro \\
\end{tabular} & $\begin{array}{c}\text { Ass. } \\
\text { Comunitárias } \\
\end{array}$ \\
\hline \multirow{3}{*}{$\begin{array}{l}\text { Organizações } \\
\text { Populares }\end{array}$} & Vínculos novos & & 3 & 2 & \begin{tabular}{|l|l|}
5 & \\
\end{tabular} & 1 & 6 & 4 \\
\hline & $\begin{array}{c}\text { Ganhos de } \\
\text { Intermediação }\end{array}$ & & 2 & 4 & 1 & 3 & 6 & 5 \\
\hline & Integração & & 2 & 1 & 4 & 3 & 6 & 5 \\
\hline \multirow{3}{*}{ Articuladoras } & Vínculos novos & 5 & & 1 & 4 & 2 & 3 & 6 \\
\hline & $\begin{array}{c}\text { Ganhos de } \\
\text { Intermediação }\end{array}$ & 2 & & 1 & 3 & 5 & 4 & 6 \\
\hline & Integração & 2 & & 1 & 3 & 4 & 5 & 6 \\
\hline \multirow{3}{*}{ ONGs } & Vínculos novos & 3 & 1 & & 4 & 2 & 5 & 6 \\
\hline & $\begin{array}{c}\text { Ganhos de } \\
\text { Intermediação }\end{array}$ & 3 & 1 & & 2 & 5 & 4 & 6 \\
\hline & Integração & 2 & 1 & & 4 & 3 & 6 & 5 \\
\hline
\end{tabular}

Tabela III : Redes de Vínculos Preferenciais ${ }^{31}$

a Ranking simples dos ganhos de interseção na rede estabelecida entre tipos de organizações civis.

O quadro pode ser completado se trazido à tona que a procura pelas organizações mais centrais, de modo especial das articuladoras, também é dominante no caso das entidades intermediárias e periféricas. De fato, conforme mostrado alhures (Gurza Lavalle, Castello e Bichir 2006c), o caráter dominante da procura por organizações mais centrais por parte de entidades periféricas é consistente e diferenciado entidades procuradas variam segundo o tipo de ator periférico - ao ponto de tornar evidente que sua estratégia de construção de relações obedece ao desafio de equacionar quais os vínculos a serem privilegiados para atingir os benefícios veiculados nos circuitos centrais. Conseqüentemente, relações entre tipos de entidades desfavorecidas por sua posição na rede não apenas são raras, mas desvalorizadas.

\section{Interpretando diferentes protagonismos}

A condição central das organizações civis, a alta densidade dos seus vínculos internos, bem como os padrões de vínculos preferenciais, encobrem significados diversos, dependendo do tipo de organização civil considerada. Por outras palavras, é possível ocupar posições similares na rede e apresentar feições relacionais semelhantes por motivos diferentes. O exame integrado dos resultados dos três recortes analíticos para

\footnotetext{
${ }^{31} \mathrm{Em}$ todos os casos considerou-se a direção das relações.
} 
cada uma das três organizações civis mais centrais, complementado com a análise dos respectivos sociogramas, permitirá iluminar esses motivos e mostrará o significado dos distintos padrões de centralidade ou protagonismos que caracterizam essas entidades.

\section{As Organizações Populares}

Organizações populares são atores engajados na disputa de questões estruturais, lançando mão, para tanto, de expedientes de mobilização e protesto que pressionam as instâncias de tomada de decisão e suscitam atenção pública. O protagonismo político identificado com as camadas pior aquinhoadas da população vem acompanhado de uma posição preponderante no universo das organizações civis. De fato, e a despeito do seu relativo "sumiço" na literatura, esses atores populares são os de maior centralidade no universo das organizações civis de São Paulo, especialmente devido a serem muito procurados e em menor medida a eles desenvolverem estratégias ativas de construção de relações (Tabela I). Sua posição privilegiada e, como será visto logo, a existência de vínculos com o tipo de entidade mais periférica fazem com que as organizações em questão se destaquem por sustentar relações assimétricas no universo das organizações civis.

Comparativamente, a articulação das organizações populares entre si parece mais relevante para sua estratégia de atuação - centrada no protesto — do que a conexão com outros tipos de entidades. A rede interna dessas organizações é a mais coesa entre todas as analisadas e apresenta notável densidade de relações, atores com forte poder de intermediação e grande proximidade entre seus integrantes, cujas posições na rede são as mais equilibradas (Tabela $\mathrm{II}$ ). ${ }^{32}$ Ademais, organizações populares alcançam-se umas as outras de modo bastante eficiente e com um número bastante baixo, em termos comparativos, de atores isolados, quer dizer, de organizações populares que não mantêm vínculos com seus pares. ${ }^{33}$ Tais características podem ser melhor compreendidas a partir do Sociograma 1. O papel ativo das organizações populares na sua articulação interna dá lugar a uma rede cujo formato se aproxima de uma "estrela", quer dizer, conforme a teoria, de uma rede hipotética de igual tamanho em que todas as relações possíveis estariam efetivamente presentes graças à intermediação de um ator central (Wasserman e Faust 1994: 169-172). Contudo, essa rede é claramente uma rede bi-nuclear, uma vez que praticamente todos os vínculos

32 Embora normalizados, neste caso os resultados exprimem em certo grau o baixo número de atores na rede das organizações populares. 
existentes são constituídos em relação a dois atores centrais, o Movimento dos Sem Terra e o Movimento dos Sem teto do Centro (mstc). O MST é a "ponte" que vincula movimentos nacionais como o Movimento Nacional de Luta pela Moradia $(\mathrm{mn} / \mathrm{m})$, e movimentos de índole rural como o Movimento dos Pequenos Agricultores (movpeqagri) e dos Atingidos por Barragens (moab), com movimentos urbanos locais, quer dizer, da cidade de São Paulo, nucleados em torno do segundo ator - Movimento de Moradia do Centro (mmc) ou Defesa do Favelado (mdf), por exemplo. A referência central, neste caso, está no ator de maior capacidade de mobilização e visibilidade pública, o MST, e não em atores que atendem demandas localizadas ou apresentam afinidades temáticas, como acontece com praticamente todos os tipos de organizações civis.

A lógica seletiva de se relacionar com atores mais centrais ou com maior capacidade de ação vale também, embora algo atenuada, para os vínculos privilegiados pelas organizações populares com outras organizações civis (Tabela III). A proximidade com as ONGs está inscrita na origem das próprias ONGs como assessoras de movimentos sociais, mas a proximidade das organizações populares com as articuladoras é fato mais recente que não tem sido apontado na literatura. Há, ainda, outros resultados inesperados: organizações populares conferem importância mínima às relações com associações de bairro e, por sinal, trata-se de uma "indiferença" completamente recíproca (Gurza Lavalle, Castello e Bichir 2006c). A construção de relações com entidades que apresentam demandas urbanas locais e de baixa visibilidade parece ser infrutífera para o ator examinado. Paradoxalmente, dentre os três tipos de entidades mais centrais, as organizações populares apresentam relativamente mais vínculos com as associações comunitárias, o que contribui para a compreensão do caráter assimétrico de suas relações quando olhadas do primeiro recorte analítico - relações com o conjunto dos atores da amostra.

A trajetória histórica das organizações populares, com suas agendas de combate à exclusão social baseada em fatores socioeconômicos, levaria a supor a presença de maior (ou pelo menos de alguma) proximidade com entidades de base popular como as associações de bairro; ainda mais se considerado que boa parte das organizações populares lida com a questão da moradia - metade no caso do Sociograma 1. Embora a análise relacional evidencie que as organizações populares continuam a ocupar

\footnotetext{
${ }^{33}$ O número de isolados será reportado na parte inferior direita de cada sociograma.
} 
posição protagônica no seio das organizações civis - em que pese o foco dominante da literatura em outro tipo de atores - , a perda de relevância das associações de bairro para essas organizações, e vice-versa, sugere deslocamentos inéditos no plano da ação coletiva durante os anos pós-transição; deslocamentos que ganharão contornos mais precisos mediante a interpretação dos outros tipos de organizações civis centrais.

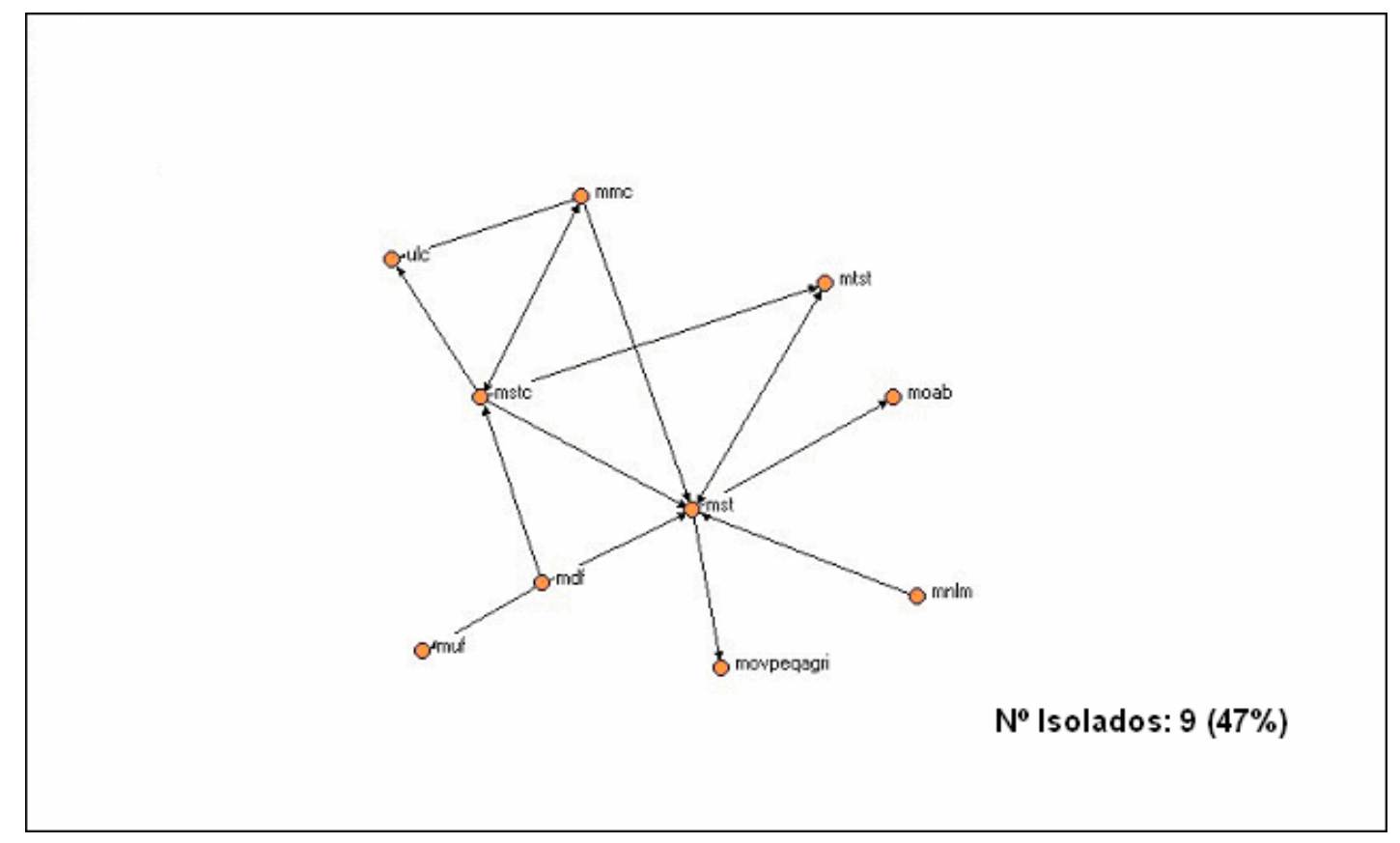

Sociograma 1: Rede Interna - Organizações Populares ${ }^{34}$

\section{As Articuladoras}

Articuladoras são atores de terceiro nível, quer dizer, exprimem o resultado dos esforços de outras organizações civis -em boa mediada das ONGs, mas não só- no sentido de ampliar e fortalecer o trabalho por elas desenvolvido mediante a institucionalização de atores com capacidade de coordenar e impulsionar as agendas dos seus membros, bem como de representá-los perante o poder público e perante outros atores políticos, econômicos e inclusive civis. Embora não surpreenda a alta centralidade das articuladoras (Tabela 1), dada sua qualidade de entidades cujos públicos são outras entidades, os resultados atestam o sucesso das iniciativas de

\footnotetext{
${ }^{34}$ Atores: Mdf - Movimento de Defesa dos Favelados; mmc - Movimento de Moradia do Centro; mnIm Movimento Nacional de Luta pela Moradia; moab - Movimento dos Atingidos por Barragens; movpeqagri Movimento dos Pequenos Agricultores; mst - Movimento dos Sem Terra; mstc - Movimento dos Sem Teto do Centro; mtst - Movimento dos Trabalhadores Sem Teto; muf - Movimento de Unificação das Favelas; ulc - Unificação de Lutas de Cortiços.
} 
criação desse novo tipo de ator nos últimos anos. Os efeitos de seu caráter de organizações de sócios ou membros institucionais também transparecem na análise relacional: elas são relativamente distantes do universo mais amplo de entidades com as quais mantêm relações e, em se tratando de entidades assim centrais, acusam capacidade limitada de alcançar outros atores - plausivelmente além dos seus próprios membros. ${ }^{35}$ Como as organizações populares, e por motivos semelhantes -alta centralidade acompanhada de vínculos com algum tipo de entidade periférica-, as articuladoras sustentam relações marcadas pela assimetria.

As relações internas das articuladoras iluminam com maior precisão sua forma de operação. De um lado, sustentam entre si relações das mais equilibradas (ausência de dependência), configurando uma rede notavelmente densa, seus padrões internos de relacionamento obedecem a clivagens claras, diminuindo a proximidade dos seus vínculos (Tabela II). O Sociograma 2 permite visualizar tais padrões. Nele se verifica que as articuladoras ordenam suas estratégias de relacionamento por afinidades temáticas, funcionais e programáticas, não raro parcialmente sobrepostas. O nicho das entidades que tratam da questão de gênero é caso de afinidade eminentemente temática, e aquele das articuladoras de associações de bairro supõe clara afinidade funcional; entretanto, as sub-redes de movimentos populares, financiadoras do terceiro setor e articuladoras religiosas combinam com peso relevante mais de uma afinidade. Nos últimos três casos, as articuladoras de cada nicho trabalham em prol de atores com um perfil específico, e, a um tempo só, disputam e representam concepções diferentes do sentido da ação coletiva na sociedade atual. De fato, dadas suas funções, importância e o custo de criar e manter entidades com semelhante perfil, a composição do universo das articuladoras acaba por projetar, como em jogo de sombras, as constelações de atores com maior peso na disputa pelo sentido da ação coletiva perante o Estado e perante os próprios atores sociais - o chamado campo de esquerda popular, o empresariado e as igrejas, respectivamente. Por fim, a despeito da densidade de relações internas, as relativas distância e dificuldade de alcançar atores decorrem do fato de os nichos dependerem de entidades ponte (gatekeepers) para se vincularem a seus pares orientados por outras afinidades; notadamente, a União Brasileira de Mulheres (ubm) para as articuladoras do movimento de gênero, a

\footnotetext{
${ }^{35}$ As entidades entrevistadas foram solicitadas a enunciar, para diversos tipos de atores, seus vínculos mais relevantes (até 5). Isso implica, no caso das articuladoras, mencionar associações além do conjunto ou perfil daquelas que as fundaram ou constituem seus membros.
} 
Confederação Nacional de Associações de Moradores (conam) para aquelas das associações de bairro, a Central dos Movimentos Populares (cmp) para as dos movimentos, e a Rede Brasileira das Entidades Assistenciais Filantrópicas (rebraf) para as articuladoras religiosas.

O exame das relações que as articuladoras estabelecem com outras associações traz à tona algumas feições que complementam a compreensão do papel deste novo ator. Embora cada tipo de organização civil sustente vínculos preferenciais com outros tipos, as relações entre articuladoras e ONGs constituem caso nítido de aliança, quer dizer, o único caso em que, nas relações entre dois tipos de atores, coincidem reciprocidade plena e importância máxima (Tabela III). ${ }^{36}$ Por outras palavras, para todas as medidas de inter-relação entre pares de entidades, as ONGs são os vínculos mais relevantes para as articuladoras e vice-versa. A aliança exprime em boa medida a origem das próprias articuladoras e, simultaneamente, mostra seus vínculos mais recorrentes, reforçando seu perfil temático. Em segundo plano, as entidades em questão estabelecem vínculos com organizações populares e, depois, com organizações civis de condição intermediária - fóruns e entidades assistenciais. Cumpre notar que a existência de articuladoras de associações de bairro franqueia o acesso dessas associações aos atores mais centrais da rede; fato evidenciado não apenas pela relativa importância das associações de bairro para as articuladoras, mas, em perspectiva inversa, pelo caráter privilegiado das relações construídas pelas primeiras com as segundas - relações das quais obtém os maiores benefícios para todas as medidas aqui trabalhadas (Gurza Lavalle, Castello e Bichir 2007).

As articuladoras nascem com a função de coordenar a ação de diversos conjuntos de atores, bem como de representar seus interesses. Se considerada tanto sua centralidade no conjunto das organizações civis quanto sua relevância para cada tipo de entidade, e, em especial, para atores periféricos como as organizações de bairro, não parece descabido apontar que os esforços de organizações civis orientados para a construção de novos atores com maior capacidade de intermediação e agregação foram não apenas bem-sucedidos para organizações altamente centrais, mas também para entidades territoriais de base - de condição periférica - que, graças à intermediação das articuladoras, ampliam sua capacidade de ação para além do plano

\footnotetext{
36 Trata-se do único caso de aliança mesmo se contemplados os resultados separados de cada tipo de organização civil dos Demais Atores.
} 
local. A ausência de relações entre organizações populares e associações de bairro e os achados apresentados acima apontam não apenas para a existência de mudanças de envergadura na ação coletiva, até agora desapercebidas na literatura - as articuladoras costumam ser classificadas como ONGs e não têm sido objeto de estudo -, mas também para a plasticidade da própria ação coletiva e para a capacidade de inovação institucional das organizações civis no sentido de incrementarem sua escala de atuação.

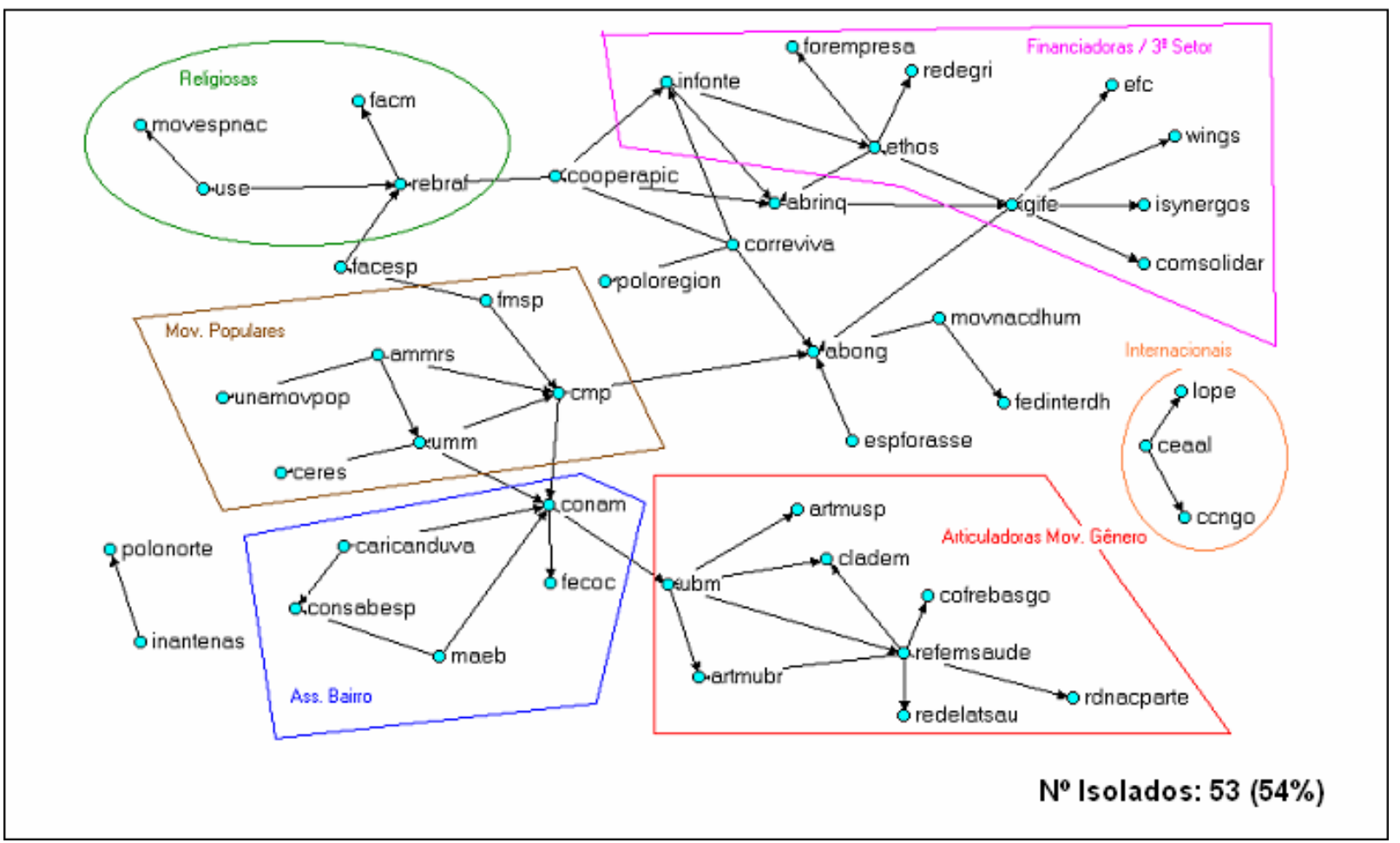

Sociograma 2: Rede Interna das Articuladoras ${ }^{37}$

37 Atores: abong - Associação Brasileira de Ongs; abrinq - Fundação Abrinq; ammrs - Associação dos Movimentos de Moradia da Região Sudeste; artmubr - Articulação de Mulheres Brasileiras; artmusp Articulação de Mulheres de São Paulo; caricanduva - Câmara do Vale do Aricanduva; ccngo - CCNGO; ceaal - Conselho de Educação de Adultos da América Latina; ceres - CERES; cladem - CLADEM; cmp Central de Movimento Populares; cofrebasgo - Comissão do FREBASGO; comsolidar - Comunidade Solidária; conam - Confederação Nacional de Associações de Moradores; consabesp - Conselho Coordenador das Sociedades Amigos de Bairro, Cidades e Vilas do Estado de São Paulo; cooperapic Cooperapic; correviva - Corrente Viva; efc - European Foundation Center; espforasse - Espaço Formação e Assessoria; ethos - Ethos; facesp - Federação das Associações Comerciais do Estado de São Paulo; facm - Federação de Ass. Cristãs de Moços; fecoc - FECOC; fedinterdh - Federação Internacional de Direitos Humanos; fmsp - Fórum dos Mutirões de São Paulo; forempresa - Fórum Empresa; gife - GIFE; inantenas - Instituto Antenas; infonte - Instituto Fonte; isynergos - Instituto Synergos; lope - Lope Rede Latino-Americana; maeb - MAEB; movespnac -.Movimento Espírita Nacional (órgão); movnacdhum -.Movimento Nacional de Direitos Humanos; polonorte - Pólo Norte; poloregion - Pólo Regional; rdnacparte - Rede Nacional de Parteiras; rebraf - REBRAF; redegri - Rede GRI (Global Reporting Iniciative); redelatsau - Rede Latino Americana de Saúde; refemsaude - Rede Feminista de Saúde; ubm - 


\section{As Ongs}

As Ongs completam os atores civis de alta centralidade e atuam mediante a tematização pública de problemas, não raro abordados a partir de uma semântica política de direitos cidadãos; isto é, são eminentemente entidades de advocacy — o que não exclui, mas subordina a prestação direta de serviços. A análise relacional revela que as atividades de advocacy das ONGs guardam conexão com uma forma de centralidade passível de ser contraposta àquela própria das organizações populares e das articuladoras: a centralidade das últimas encerra um componente passivo, quer dizer, são mais procuradas diretamente do que procuram e, na rede como um todo, apresentam balanço favorável de vínculos indiretos; já a centralidade das ONGs segue um perfil ativo, pois se trata do tipo de organização civil que mais constrói vínculos mais procura do que é procurado - , além de ser menos próximo das organizações que o citam como parceiras do que daquelas com as quais entabula ativamente relações (Tabela 1). A idéia de as ONGs trabalharem em rede encontra-se amplamente presente na literatura, todavia, quando assumidos os pressupostos da análise de redes, tal afirmação torna-se um truísmo, visto que o ponto de partida é o caráter relacional do mundo. Os resultados permitem qualificar melhor o perfil das ONGs como construtoras de vínculos ou atores centrais ativos - por sinal, os mais eficientes quanto à capacidade de alcançar outras entidades ou locais da rede. Outra feição distintiva das ONGs, cujo significado tornar-se-á claro graças aos outros recortes analíticos, é o caráter marcadamente simétrico das relações por elas construídas, pois se trata das entidades que criam menor dependência nos seus relacionamentos dentro do universo das organizações civis.

A rede interna de ONGs é notavelmente coesa, a despeito de ser muito numerosa (Tabela II). Seu perfil como construtoras ativas de relações e como entidades de advocacy adquire concreção, no plano das suas relações internas, como uma especialização temática acentuada que, no entanto, vem acompanhada mais uma vez da maior eficiência para alcançar diferentes atores, mas agora acrescida da maior disponibilidade de caminhos rápidos para alcançá-los. Apesar da coesão interna, tratase de uma rede relativamente descentralizada e com o menor número de atores isolados de todas as redes internas sob exame (apenas 36\%) — inclusive se

União Brasileira de Mulheres; umm - União dos Movimentos de Moradia; unamovpop - União Nacional de Movimentos Populares; use - União das Sociedades Espíritas; wings - Wings. 
considerados de modo separado os tipos aglutinados nos Demais Atores (ver Gurza Lavalle, Castello e Bichir 2007). O Sociograma $3^{38}$ permite verificar, precisamente, que a especificidade das relações entre ONGs está na constituição de vínculos múltiplos, sempre orientados por uma lógica temática, ou seja, dirigidos para organizações civis que trabalham em prol do mesmo tema: os nichos compostos por entidades dedicadas, por exemplo, aos temas da Educação, de Gênero e Raça, da habitação, de crianças deficientes ou da violência. ${ }^{39}$ A despeito de se articularem em sub-redes temáticas, a construção de vínculos múltiplos inibe, salvo raras exceções, a presença de atores ponte ou intermediários indispensáveis - como ocorre no caso das articuladoras. ${ }^{40}$ Por outro lado, também se observam sub-redes que não apresentam interação com os

38 Atores: abdecegos - Ass. Brasileira de Desporto para Cegos; acaocidada - Ação da Cidadania acaoeduca - Ação Educativa; actionaid - Action Aid; agende - Agende; ahortoflor - Associação Horto Florestal; Alovida - Alô Vida; Amam - Associação das Mulheres que Amam Mulheres; amaosmine Associação Mãos Mineiras - MG; amencar - AMENCAR; apoio - Apoio; asbereana -Associação Bereana; aschicomen -Associação Chico Mendes; assevoldh - Ass. Evoluir e Desenvolvimento Humano; asspe Associação Santista para Prevenção a Educação; asspromsluis -Associação Pró-Moradia do Jd. São Luis; billings - Billings que eu te quero Viva; caap - Centro de Assessoria à Auto-Gestão Popular; cacumuneg Casa da Cultura da Mulher Negra; caico - CAICO; capacitsol- Capacitação Solidária; casasolida - Casa da Solidariedade; catddecarg - Católicas pelo Direito de Decidir Argentina; catddecbol - Católicas pelo Direito de Decidir Bolívia; catddechil - Católicas pelo Direito de Decidir Chile; catddecmex - Católicas pelo Direito de Decidir México; catdirdec - Católicas pelo Direito de Decidir; cdefcripmp - Centro de Defesa da Criança Pe. Marcos Pordrini; cdi - CDI; cecir - CECIR - Centro Cidra Romano; cedac - CEDAC; cedeca Centro de Defesa dos Direitos da Criança e do Adolescente; cedhep - CEDHEP - Centro de Direitos Humanos de Educação Popular; ceep - CEEP; cengasgarc - Centro Gaspar Garcia; cenpec - Cenpec; cenvolunt Centro de Voluntariado; cesec - CESEC; cfl - CFL; coletivfem - Coletivo Feminista; comitebet - Comitê Betinho; corsa - CORSA; cria - Cria; criola - CRIOLA (RJ); croph - Centro de Promoção Humana; cruzaproin - Cruzada Pró-Infância; csnsbparto - Centro Social Nossa Senhora do Bom Parto; csparelhe Centro Social de Parelheiros; cssaojose - Centro Social São José; defendasp - Defenda São Paulo; ecos ECOS; entrafrate - Entraide et Fraternité (Belga); entreamigo - Entreamigos; escfuturo - Escola do Futuro; esplar - ESPLAR; falanegao - Fala Negão; falapreta - Fala Preta; fase - Fase; fundorsa Fundação Orsa; funfeale - Fundação Fé e Alegria; funfrafran - Fundação Francisca Franco; funprojtra Fundação Projeto Travessia; geledes - Geledés; gpicenvida - Grupo de Incentivo à Vida; gpidentid Grupo Identidade; gptornunma - Grupo Tortura Nunca Mais; gtpos - GTPOS; ialode - IALODE (BA); ibase - IBASE; ibeac - IBEAC; inavisala - Instituto Avisa Lá; incinelem - Instituto 5 Elementos; indestrab Instituto de Desenvolvimento do Trabalhador; ingovciabc - Instituto de Governo e Cidadania do ABC; inkaplan - Instituto Kaplan; inremivida - Instituto Recicle milhões de Vidas; insakatu - Instituto Akatu; inspconvio - Instituto São Paulo contra a Violência; inspfreire - Instituto Paulo Freire; insterra - Instituto Terra; instgea - Instituto GEA; integra - Integra; isoudapaz - Instituto Sou da Paz; its - ITS (Instituto de Tecnologia Social); jusglobal - Justiça Global; lac - Liga de Assessoria Comunitária; moc - Movimento de Organização Comunitária - BA; motiva - Motiva; mova - MOVA; movmenrua - Movimento de Meninos e Meninas de Rua; movneguni - Movimento Negro Unificado; mriscurb - Movimento de Prevenção aos Riscos Urbanos; mundoafro - Mundo Afro (Uruguai); musa - MUSA (Belo Horizonte); netmal - Núcleo de Estudos Tecnológicos da Mulher na América Latina; novib - Novib; numorung - Núcleo Morungaba; oaf Organização do Auxílio Fraterno; orgmuntort - Organização Mundial Contra a Tortura; oxfon - OXFON; polis - Polis; politevo - Politevo; prabiru - Prabirú; proaung - Pro Aung; projaprend - Projeto Aprendiz; promundo - Pró-Mundo; redejovem - Rede Jovem; redemulher - Rede Mulher; redesocjdh Rede Social de Justiça e Direitos Humanos; renadvpop - Rede Nacional de Advogados e Advogadas Populares; sof - Sempre Viva Organização Feminina; sorribrasil - Sorri-Brasil; sos - SOS; umoutrool Um outro olhar; unimulher - União de Mulheres; usina - USINA; vereda - Vereda; vitae - Vitae; vivacentro - Viva o Centro; votoconsci -Voto Consciente.

39 Apenas foram destacados os maiores nichos temáticos para permitir a visibilidade da informação apresentada. 
demais nichos: entidades que lidam com a questão da violência ou de crianças deficientes. Assim, a lógica temática a um só tempo constrange e viabiliza a interação de determinados nichos com a rede mais ampla de ONGs. A esse respeito resulta emblemático o caso das entidades dedicadas à questão da homossexualidade, cujos atores apenas conseguem estabelecer relações com outros nichos da rede através das relações com organizações de gênero.

À coesão, densidade e perfil temático da rede é preciso acrescer mais duas feições. Em parte devido ao grande número de entidades na rede interna das ONGs, a proximidade entre seus integrantes é baixa e, ao contrário do que ocorre nas relações dessas entidades com as outras organizações civis, os vínculos internos são assimétricos, ou seja, as relações entre ONGs são consideravelmente hierárquicas. A combinação entre a simetria das relações das ONGs com a rede como um todo e a dependência gerada pelos vínculos com seus pares contrasta com padrão inverso dos outros dois tipos de organizações civis centrais - organizações populares e articuladoras combinam horizontalidade nas relações internas com aguda assimetria nos vínculos por elas estabelecidos com o conjunto das organizações civis. Semelhante contraste não parece decorrer apenas do maior tamanho das redes internas das ONGs, mas do perfil ativo e passivo que diferencia os padrões de centralidade desses três tipos de atores, bem como dos vínculos preferenciais por eles estabelecidos.

Quando observados os vínculos privilegiados pelas ONGs com outros tipos de organizações civis (Tabela III), emerge primeiro sua aliança com as articuladoras — já abordada -, e, depois, os vínculos estabelecidos com organizações populares, seguidos daqueles construídos com fóruns e entidades assistenciais. Como era de se esperar a partir dos padrões mais gerais, relações com associações que obedecem à lógica de demandas populares específicas, como as comunitárias e associações de bairro, mostram-se pouco importantes. Por isso, diferentemente das organizações populares e das articuladoras, que cultivam em algum grau relações com os dois últimos tipos de organizações, ONGs não acusam relações assimétricas no conjunto da rede.

Em suma, as ONGs notabilizam-se não apenas por serem os principais construtores de relações do universo de organizações civis estudado, mas por terem contribuído

\footnotetext{
40 Para citar apenas dois exemplos, atores quase indispensáveis para conectar diferentes nichos são: Coletivo Feminista (coletivfem) e Ação Cidadão (acaocidada).
} 
decisivamente à criação de um novo tipo de entidades com notável capacidade de ação, coordenação e agregação. A aliança entre ONGs e articuladoras sinaliza emblematicamente a trajetória das primeiras e a consolidação do seu protagonismo no contexto pós-transição: originadas como entidades de assessoria aos movimentos populares (organizações populares), acabaram por se desvencilhar da sua missão inicial assumindo funções próprias na disputa da agenda pública e da formulação, fiscalização e, por vezes, implantação de políticas públicas. Hoje, são as articuladoras e não as organizações populares que definem o repertório estratégico de relações das ONGs. As funções assumidas e politicamente construídas ao longo dessa trajetória correm paralelas a sua acentuada especialização temática e a sua diferenciação e hierarquização internas. 
REDES- Revista hispana para el análisis de redes sociales

Vol.12,\#6, Junio 2007

http://revista-redes.rediris.es

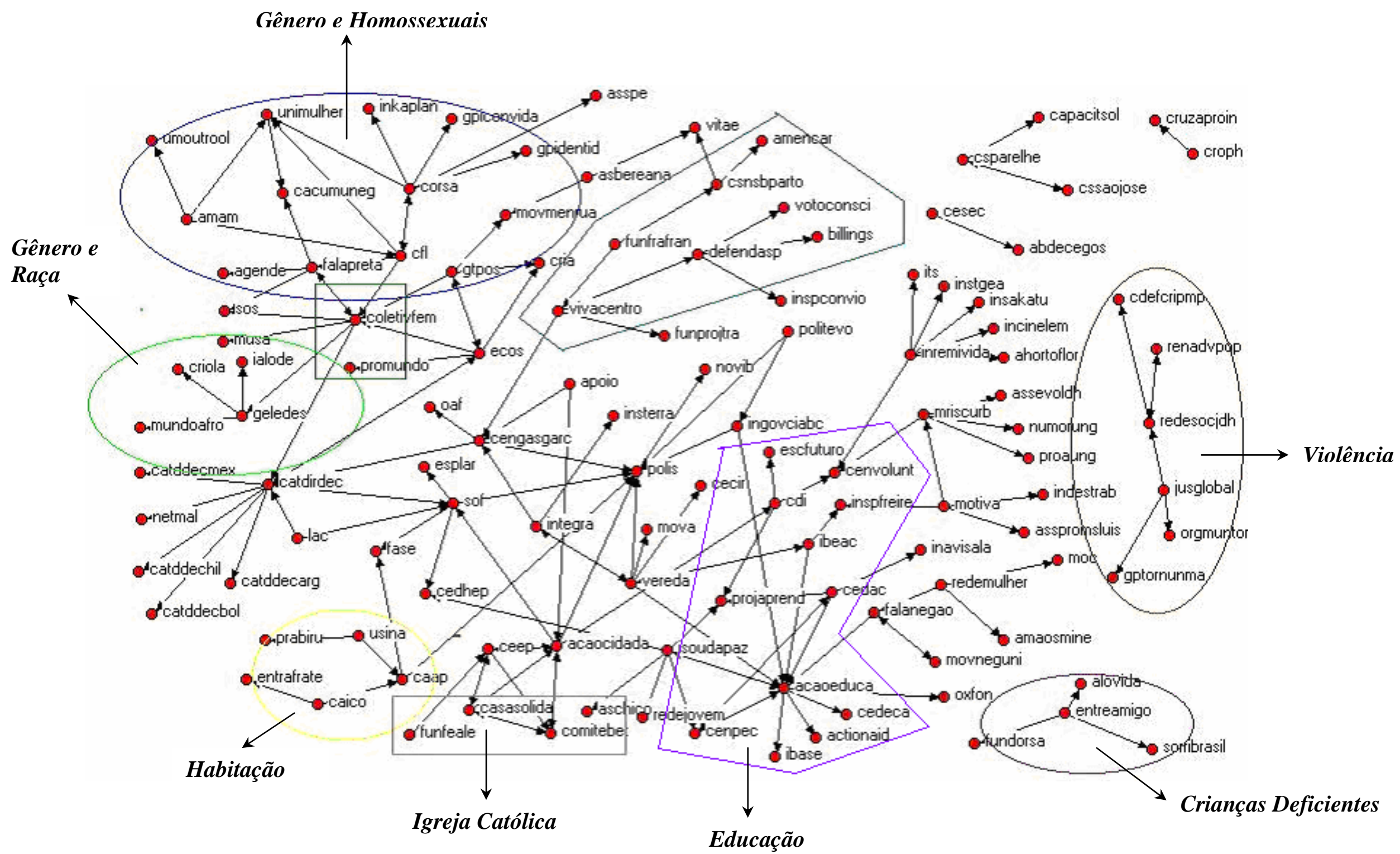

Sociograma 3: Rede Interna ONGs. No Isolados: 59 (33\%) 


\section{Comentário final}

A interpretação dos achados apresentados nas páginas deste artigo ilumina de ângulos diversos a atuação das organizações civis mais centrais e apontam para lacunas no estado do conhecimento desses atores; lacunas que para serem sanadas exigem a construção coletiva de uma vasta agenda de pesquisa, na qual abordagens relacionais e, mais especificamente, a análise de redes, constituem estratégias conceituais e metodológicas de enorme valia. A abordagem relacional mostra que — pelo menos em São Paulo- o universo das organizações civis é hierárquico e desigual quanto às capacidades de ação e de interlocução. Organizações populares, articuladoras e ONGs são os grandes protagonistas da rede com padrões de centralidade diferenciados, quer dizer, os atores que, por motivos diferentes, se desempenham como referência para entidades menos centrais ou francamente periféricas. Por sua vez, as organizações civis mais centrais são simultaneamente aquelas com investimentos maiores na construção de relações internas ou com seus próprios pares, e aquelas mais procuradas pelas próprias entidades centrais, bem como pelas entidades periféricas e intermediárias.

Nestas páginas há evidências tanto do caráter impreciso ou apressado de alguns consensos na literatura quanto de transformações de envergadura sem tratamento ou estudo adequado. Movimentos sociais (organizações populares), por exemplo, distam de ter submergido no marasmo em que os prostrou a literatura a partir da onda de balanços que marcara a passagem dos anos 1980 para a década seguinte. Eles são ao atores mais centrais no universo das organizações civis pesquisadas e, no entanto, experimentaram processo de transformação do seu perfil. De outro lado, as articuladoras são produto notável de uma estratégia bem sucedida de criação de atores que reflete $o$ adensamento e diferenciação funcional do universo das organizações civis. Sua centralidade não apenas atesta a capacidade de construção institucional das organizações civis, em particular das ONGs, mas ilumina a plasticidade da ação coletiva no sentido de inovar para escalar demandas e problemas, bem como para representar interesses e perfilar agendas compartilhadas por constelações amplas de atores sociais.

Hierarquização e desigualdades estruturais na capacidade de ação e comunicação, mas sobretudo o caráter cumulativo das vantagens estruturais, apontados nestas páginas, sugerem críticas e levantam uma série de problemas para teoria da sociedade civil, bem como a sua junção com o debate em curso no campo da teoria democrática - 
não abordados nestas páginas. ${ }^{41}$ O quão corrosivos possam eventualmente ser achados como estes depende, em boa medida, do grau de exigências normativas introduzidas pela teoria, bem como do papel que tais exigências desempenham no diagnóstico do mundo. Seja como for, os resultados são persuasivos sobre dois aspectos passíveis de interpretação a partir de diferentes registros teóricos: primeiro, os alcances da atuação das organizações civis mal podem ser compreendidos se desconsiderados os processos de diferenciação funcional impulsionados intencionalmente por esses atores para incrementar suas chances de incidência nas instâncias pertinentes de tomada de decisões ou na conformação da agenda pública; segundo, a ação coletiva no contexto da pós-transição acusa mudanças relevantes, mas sem abordagens sistemáticas e comparativas do universo das organizações civis, o tratamento do assunto carece de parâmetros e corre o riscos de descansar em apreciações "impressionistas".

\section{Bibliografia}

Atkinson, R. and Flint, J.(2003). "Accessing hidden and hard-to-reach populations: snowball research strategies", Social Research Update 33, www.soc.surrey.ac.uk/sru/SRU33.html

Avritzer, Leonardo (2003). Democracy and the Public Space in Latin America. Princeton: Princeton University Press.

Borgatti, Everett \& Freeman (2002). Ucinet - Software of Social Network Analysis User's Guide. Analytic Technologies, Inc.

Borja, Jordi (1981). "Movimientos urbanos y cambio político". In Mario Bassols, Roberto Donoso, et. al., Antología de Sociología Urbana. México, UNAM, 1988, pp. 801-29.

Cardoso, Ruth Corrêa Leite. (1994) "A trajetória dos movimentos sociais", in Dagnino, Evelina (org.), Anos 90 - política e sociedade no Brasil, São Paulo, Brasiliense, pp. 81-90.

Carvalho, Maria do Carmo Brant.(1998) "Sociedade civil, Estado e terceiro setor". São Paulo em Perspectiva, vol 12, no 4, outubro/dezembro 1998.

Casanovas, Roberto Sainz e CHACóN, Oscar Garcia.(2000) Las ONGs Latinoamericanas y los desafíos del desarrollo organizacional. Bolivia, ICCO/ PROACTIVA/ IDEPRO, pp. 28-38, 63-74.

\footnotetext{
${ }^{41}$ Notadamente no que diz respeito à junção com as teorias deliberativa e participativa da democracia.
} 
Castells, Manuel. "Los movimientos sociales urbanos en la via democrática al socialismo". (1979) In Mario Bassols, Roberto Donoso, et. al., Antología de Sociología Urbana, México, UNAM, 1988, pp. 777-83.

Coelho, Simone de Castro Tavares. (2000) Terceiro setor: Um estudo comparado entre Brasil e Estados Unidos. São Paulo, SENAC, 2000, pp. 57-80.

Cohen, Jean e Arato, Andrew (1995). Sociedad civil y teoría Política. México, Fondo de Cultura Económica.

Cunha, Flávio S. (1993). "Movimentos sociais urbanos e a redemocratização: a experiência do movimento favelado de Belo Horizonte", pp. 134-135, 142; Novos Estudos, n. 35, março.

Diani, Mario and McAdam, Dough (2003). Social Movements and Networks. Relational Approaches to Collective Action. Oxford University Press.

Emirbayer, (1997). "Manifesto for a relational sociology", American Journal of Sociology, Vol 103, n.2.

Evers, Tilman.(1984) "Identidade - A face oculta dos movimentos sociais", Novos Estudos, no 4, pp. 11-23.

Feltran, Gabriel. (2005). Desvelar a política na periferia: História de movimentos sociais em São Paulo. São Paulo: Associação Editorial Humanitas, Fapesp.

Fernandes, Rubem César (1994). Privado, porém público - O terceiro setor na América Latina. Rio do Janeiro, Relume Dumará / Civicus.

Fleury, Sônia (1994). Estado sem cidadãos - Seguridade social na América Latina. Riode Janeiro, Fiocrusz.

Fung, Archon e WRIGHT Eric Olin (2003). "Thinking about Empowered Participatory Governance." In Fung, Archon e Wright Eric Olin (eds). Deepening Democracy: Institutional Innovation in Empowered Participatory Governance. London: Verso.

Gohn, Maria da Glória (org) (2003). Movimentos Sociais no início do século XXI. Petrópolis/RJ: Vozes.

- (1997). Teorias dos movimentos sociais - Paradigmas clássicos e contemporâneos. São Paulo, Edições Loyola.

Goodman, L. (1961). "Snowball sampling", Annals of Mathematical Statistics, v. 32, n 1.

Götz, Ottmann (1995). "Movimentos sociais urbanos e democracia no Brasil - Uma abordagem cognitiva", Novos Estudos, no 41, CEBRAP, março, pp. 186-207.

Gurza Lavalle, Adrián (1999). "Crítica ao Modelo da Nova Sociedade Civil", Lua Nova no 47.

- (2003). "Sem pena nem gloria. O debate da sociedade civil nos anos 1990", Novos Estudos, no 66, julho, pp. 91-110. 
Gurza Lavalle, Adrián; Castello, Graziela e Bichir, Renata M. (2004a). "Quando Novos Atores Saem de Cena: Continuidades e Mudanças na Centralidade dos Movimentos Sociais". Cultura e Política, UFSC, Santa Catarina: vol 10, no 2.

- (2006). "Os Bastidores da Sociedade Civil — Protagonismo, redes e afinidades no seio das organizações civis". CEBRAP, mimeo.

- (2007) "Behind the Scenes: Roles, Centrality and Networks within Civil Society. Lessons from São Paulo". IDS Working Paper Series, Brighton, no prelo.

Gurza Lavalle, Adrián; Houtzager, Peter e Acharya, Arnab (2004b). "Lugares e atores da democracia - Arranjos institucionais participativos e sociedade civil em São Paulo". In, Schattan Vera e Nobre Marcos (orgs). Participação e deliberação Teoria democrática e experiências institucionais no Brasil contemporâneo. São Paulo: Editora 34, 2004.

- (2005). "Beyond Comparative Anecdotalism: Lesson on Civil Society and Participation from São Paulo, Brazil". World Development Journal. Estados Unidos: v.33, n.n. 6.

Gurza Lavalle, Adrián; Houtzager, Peter e Castello, Graziela. (2006a). "Democracia, Pluralização da Representação e Sociedade Civil". Lua Nova: Revista de Cultura e Política. São Paulo: n. 67.

- (2006b). "Representação Política e Organizações Civis - Novas Instâncias de Mediação e os Desafios da Legitimidade". Revista Brasileira de Ciências Sociais, v. 21, n. 60.

Hanneman, Robert A. (2001). Introduction to social network methods. Disponível em: http://faculty.ucr.edu/ hanneman/SOC157/NETTEXT.PDF.

Heller, P., forthcoming, "Reinventing Public Power in the Age of Globalization: The Transformation of Movement Politics in Kerala", in R. Ray and M. Fainsod Katzenstein (eds). Social Movements and Poverty in India. Unpublished manuscript.

Houtzager, P., Berins Collier, R., Harriss, J. and Gurza Lavalle, A., (2002), "Rights, representation and the poor: comparisons across Latin America and India", Destin Working Paper 02-31, London: London School of Economics

Houtzager, P., Gurza Lavalle, A. and Acharya, A. (2003), "Who participates? Civil society and the new democratic politics in São Paulo, Brazil", IDS Working Paper 210, Brighton: Institute of Development Studies.

- (2004). "Atores da Sociedade Civil e Atores Políticos: Participação nas Novas Políticas Democráticas em São Paulo". In Leonardo Avritzer (ed). O Associativismo em São Paulo. São Paulo: UNESP.

Klandermans, Bert, e Tarrow Sidney.(1988) "Mobilization in to Social Movements: Synthesizing European and American Aproaches". International Social Movements Research, pp. 1-38. 
Landim, Leilah (1998). "'Experiência militante': histórias das assim chamadas ONGs". In: _ (org.). Ações em sociedade - Militâncias, caridade, assistência, etc. Rio de Janeiro, ISER/NAU, pp. 23-88.

- (1996). "Notas para um perfil das ONGs". In: e Cotrim, Letícia Ligneul. ONGs: um Perfil. São Paulo. ABONG/ ISER, 1996. pp. IX-XX.

- (2002). "Múltiplas identidads das ONG's". In: Haddad Sérgio (org.). ONGs e universidades - Desafios para cooperação na América Latina. São Paulo, ABONG, pp. 17-50.

Marques, Eduardo. (2003). Redes Sociais, Instituições e Atores Políticos no Governo da Cidade de São Paulo. Ed. Annablume, São Paulo, 2003.

- (2000). Estado e Redes Sociais: Permeabilidade e Coesão nas políticas urbanas no Rio de Janeiro. Revan/ Fapesp, Rio de Janeiro/ São Paulo.

Marteleto, Regina Maria; Ribeiro, Leila Beatriz e Guimarães, Cátia. (2002). "Informação em Movimento. Produção e organização do conhecimento nos espaços sociais". Civitas, ano 2, no 1, Porto Alegre, junho de 2002.

Melucci, Alberto. (1989) "Um objetivo para os movimentos sociais?". Lua Nova, no 17, CEDEC, junho, pp. 49-66.

Mendonça, Daniel. (2002). "Para além da lei. Agonismo como princípio de ação dos movimento sociais." Civitas, ano 2, no 1, Porto Alegre, junho.

Nunes, Edison. (1987). "Movimentos populares na transição inconclusa". Lua Nova, no 13 , pp. 92-94.

Olvera, Alberto. (2003). Sociedad Civil, Esfera Pública y Democratización em América Latina: México. Universidad Veracruzana, Fondo de Cultura Económica, México, D.F.

Paz, Rosângela. (2005). Organizações Não-Governamentais: Um Debate Sobre a I dentidade Política das Associadas à Abong. Cadernos Abong, n. 33, junho.

PNUD. (1993) Informe sobre desarrollo humano. Madri, PNUD/CIDEAL.

Rucht, Dieter. (2002). "Sociedade como projeto - projetos na sociedade. Sobre o papel dos movimentos sociais". Civitas, ano 2, no 1, Porto Alegre, junho de 2002.

Sader, Eder. (1988). Quando novos personagens entram em cena - experiências, falas e lutas dos trabalhadores da Grande São Paulo (1970-80). São Paulo: Paz e Terra.

Santos, B. de Sousa. (2002) "Para Ampliar O Cânone Democrático", in Boaventura de Sousa Santos (ed.), Democratizar a Democracia: Os Caminhos da Democracia Participativa, Rio de Janeiro: Civilização Brasileira .

Scherer-Warren, Ilse.(1996). Redes de movimentos sociais. São Paulo: Ed. Loyola. 
Scott, J. (1992). Social Network analysis. Newbury Park, California: Sage Publications

Singer, Paul e Brant, Vinicius Calderia (orgs.). (1980). São Paulo: O povo em movimento. São Paulo, Vozes/CEBRAP.

Sobottka, Emil A. (2002). "Apresentação: Organizações e movimentos sociais".Civitas, ano 2, no 1, Porto Alegre, junho de 2002.

Sudman, S. and Kalton, G. (1986). "New developments in the sampling of special populations", Annual Review of Sociology 12: 401-29

Touraine, Alain.(1989). "Os novos conflitos sociais - para evitar mal-entendidos". (1983) Lua Nova, no 17, CEDEC, junho, pp. 5-18.

Wasserman, S. e Faust, K. (1994). Social network analysis: methods and applications. Structural Analysis in the social sciences. Vol 8. Cambridge: Cambridge University Press.

World Bank. (2001) World Development Report 2000/2001: Attacking Poverty, New York: Oxford University Press

- (1997) World Development Report 1997: The State in a Changing World, New York: Oxford University Press.

UNDP.(2002). Human Development Report: Deepening Democracy in a Fragmented World, New York: UNDP. 